\title{
Intestinal microbiota: a new force in cancer immunotherapy
}

\author{
Zhujiang Dai ${ }^{1 \dagger}$, Jingqiu Zhang ${ }^{2 \dagger}$, Qi Wu ${ }^{1}$, Huiwen Fang ${ }^{1}$, Chunfeng Shi ${ }^{1}$, Zhen Li ${ }^{1}$, Chaobiao Lin ${ }^{1}$, Dong Tang ${ }^{2^{*}}$ and \\ Daorong Wang $^{2^{*}}$
}

\begin{abstract}
Cancer displays high levels of heterogeneity and mutation potential, and curing cancer remains a challenge that clinicians and researchers are eager to overcome. In recent years, the emergence of cancer immunotherapy has brought hope to many patients with cancer. Cancer immunotherapy reactivates the immune function of immune cells by blocking immune checkpoints, thereby restoring the anti-tumor activity of immune cells. However, immune-related adverse events are a common complication of checkpoint blockade, which might be caused by the physiological role of checkpoint pathways in regulating adaptive immunity and preventing autoimmunity. In this context, the intestinal microbiota has shown great potential in the immunotherapy of cancer. The intestinal microbiota not only regulates the immune function of the body, but also optimizes the therapeutic effect of immune checkpoint inhibitors, thus reducing the occurrence of complications. Therefore, manipulating the intestinal microbiota is expected to enhance the effectiveness of immune checkpoint inhibitors and reduce adverse reactions, which will lead to new breakthroughs in immunotherapy and cancer management.
\end{abstract}

Keywords: Microbiota, Cancer immunotherapy, Checkpoint, PD-1, PD-L1, CTLA-4, ICls, FMT

\section{Background}

Current treatments are unable to cure many cancers, mainly because of cancer's ability to evade immune surveillance or anti-tumor disorders caused by impaired immune function [1]. In the last few years, the study of the regulation of the immune response through immune checkpoints has led to a breakthrough in therapeutic strategies in the field of oncology, bringing hope to many patients with cancer. Cancer immunotherapy reactivates the immune function of immune cells by blocking immune checkpoints (e.g., programmed death receptor 1/programmed death ligand 1 (PD-1/PD-L1), cytotoxic $\mathrm{T}$ lymphocyte antigen 4 (CTLA-4)) and restores the anti-tumor activity of immune cells [2, 3].

\footnotetext{
* Correspondence: 83392785@qq.com; daorong666@sina.com

'Zhujiang Dai and Jingqiu Zhang contributed equally to this work. ${ }^{2}$ Department of General Surgery, Institute of General Surgery, Clinical Medical College, Yangzhou University, Northern Jiangsu People's Hospital, Yangzhou 225001, P. R. China

Full list of author information is available at the end of the article
}

Based on considerable preclinical and clinical evidence, some immunotherapeutic drugs have been approved by the Food and Drug Administration (FDA) to treat various malignancies [4]. However, as the use of immunotherapy drugs in clinics increases, the blockade of immune checkpoints will cause an imbalance between autoimmune and immune tolerance, causing immunerelated adverse events [5].

Meanwhile, sequencing technology has developed rapidly in recent years. Compared with traditional microbial culture techniques, molecular techniques using $16 \mathrm{~S}$ rRNA or DNA / sequencing / metagenomics methods have provided more information on the microbiome and have revealed some potential immune functions of the intestinal microbiota [6, 7]. Therefore, researchers have gradually shifted their focus to study the relationship between the microbiota and cancer immunity. A growing body of evidence supports the role of microbiota in the treatment of cancer, particularly the response of the

(c) The Author(s). 2020 Open Access This article is licensed under a Creative Commons Attribution 4.0 International License, which permits use, sharing, adaptation, distribution and reproduction in any medium or format, as long as you give appropriate credit to the original author(s) and the source, provide a link to the Creative Commons licence, and indicate if changes were made. The images or other third party material in this article are included in the article's Creative Commons licence, unless indicated otherwise in a credit line to the material. If material is not included in the article's Creative Commons licence and your intended use is not permitted by statutory regulation or exceeds the permitted use, you will need to obtain permission directly from the copyright holder. To view a copy of this licence, visit http://creativecommons.org/licenses/by/4.0/ The Creative Commons Public Domain Dedication waiver (http://creativecommons.org/publicdomain/zero/1.0/) applies to the data made available in this article, unless otherwise stated in a credit line to the data. 
microbiota to blockade of cancer immune checkpoints $[8,9]$. In the present review, we discuss the possible mechanisms of the microbiota's effects on tumor immunotherapy and the advantages of common immunotherapies. The intestinal microbiota can improve cancer immunotherapy and patient prognosis; therefore, manipulating the microbiota will become a new force to improve cancer immunotherapy.

\section{Intestinal microbiota regulates immune responses in the body}

The intestines are the main location of the hundreds of millions of microbes that form the microbiota. The intestinal microbiota is essential in metabolism and immunity of the host; therefore, it is considered to be an invisible organ of the human body [10]. The immune function of the microbiota starts at the intestinal level and progresses to the systemic level during an immune response.

The intestinal epithelium is a mucosal tissue, of which intestinal epithelial cells (IECs) and intraepithelial lymphocytes are the major components. Paneth cells and goblet cells are embedded between IECs, which secrete antimicrobial peptides (AMPs) and mucus, to form the first line of defense against invading pathogens. The lamina propria is located below the mucosal layer, consisting of Peyer's plaques and immune cells [11]. Pattern recognition receptors (PRRs) are part of innate immunity and are mainly expressed in immune cells [12]. They are considered to be the bridge between innate immunity and adaptive immunity. PRRs recognize pathogenassociated molecular patterns (PAMPs) and damagerelated molecular patterns (DAMPs) that affect the colonization of the intestinal microbiota. Among the more typical PRRs associated with microbial homeostasis are Toll-like receptors (TLRs) and NOD-like receptors (NLRs) [13, 14]. TLRs bind to cell membranes and effect signal transduction through myeloid differentiation of primary response protein 88 (MYD88) and TIR-domaincontaining adapter-inducing interferon- $\beta$ (TRIF) [15]. Most TLR signals are transmitted through MYD88, while the signals of TLR3 and some TLR4s are transmitted through TRIF [16]. TLR1, 2, and 4-6 are expressed on the cell surface and can recognize extracellular microbes, while TLR3 and TLR7-9 are thought to detect and recognize virus particles [17]. TLR2 interacts with ligands, including bacterial lipopeptides and lipoprotein acids, and forms heterodimers with TLR1 or TLR6 [15]. Then, the heterodimer binds to MYD88 and activates the nuclear factor kappa B (NF-kB) pathway under the induction of IL-1R-associated kinases 1, 2, and 4 (IRAK1, 2, and 4) [18]. However, TLR4, with lipopolysaccharide as its ligand, requires another adapter, namely the TRIF-related adaptor molecule (TRAM), to bind to
TRIF [19]. The complex formed by TLR4 and TRIF then combines with MYD88 to form a common MYD88dependent NF-кB pathway [20]. After the MYD88-NF$\mathrm{\kappa B}$ pathway is activated, pro-inflammatory factors begin to be released, initiating the inflammatory response [20]. In addition, deletion of the MYD88 signal in epithelial cells contributes to an increase in the quantity of the mucus-associated microbiota and its' translocation to the mesenteric lymph nodes (mLNs) [21, 22] (Fig. 1). Research also showed that TLRs were strongly expressed in human colorectal cancer cells, especially TLR2 and TLR4 [23]. TLR5 is a special TLR that is thought to be related to the prevention of microbiological diseases, especially intestinal lesions caused by pathogenic adhesion of Escherichia coli. When TLR5 is lacking, E. coli flagellin cannot transmit signals through TLR5, which limits the body's immune response [24]. TLR5-deficient mice are prone to overeating and to develop metabolic syndrome compared with wild-type mice [25]. The use of antibiotics could correct this metabolic phenotype.

NOD-like receptors (NLRs) are another class of PRRs associated with microbial disorders. The NLR family includes NODs (nucleotide-binding oligomerization domain-1), NLRPs (NACHT-, LRR- and pyrin-domaincontaining proteins), IPAF (ICE-protease activating factor), NAIPs (neuronal apoptosis inhibitor factors), and class II major histocompatibility complex transactivator (CIITA) [19]. Some NLRs can identify microbial components. NOD1 and NOD2 sense the components of peptidoglycan (PGN) in the cell walls of the microbiota [15]. In this process, NOD1 is activated by $\gamma$-D-glutamylmeso-diaminopimelic acid (iE-DAP), while NOD2 is activated by muramyl dipeptide (MDP) [26]. iE-DAP is not as widespread as MDP, only being found in the cell wall of gram-negative bacteria and a small number of grampositive bacteria [27]. Therefore, NOD2 is always used as a general bacterial sensor to transmit inflammation signals. NODs are very active in the intestine and can recognize caspase recruitment domains (CARD-CARD) [28]. In the presence of CARD-CARD, NODs immediately form oligomers when stimulated by PGN and compete to recruit receptor interacting protein 2 (RIP2) kinase [19]. Then, the NOD1-RIP2 or NOD2-RIP2 complex further triggers the activation of transforming growth factor $\beta$-activated kinase 1 (TAK1) and NF- $\kappa \mathrm{B}$, thus inducing inflammation [29]. TAK1 also phosphorylates mitogen activated protein kinase (MAPK), JUN Nterminal kinase (JNK), and extracellular activated kinase (ERK), and promotes the expression of transcription factor activated protein-1 (AP-1), which causes the release of proinflammatory mediators [30].

Other NLRs, namely NLRP1, NLRP3, NLRP6, and IPAF, are mainly involved in the assembly of inflammasomes [19]. NLRP1 can be activated by the lethal 


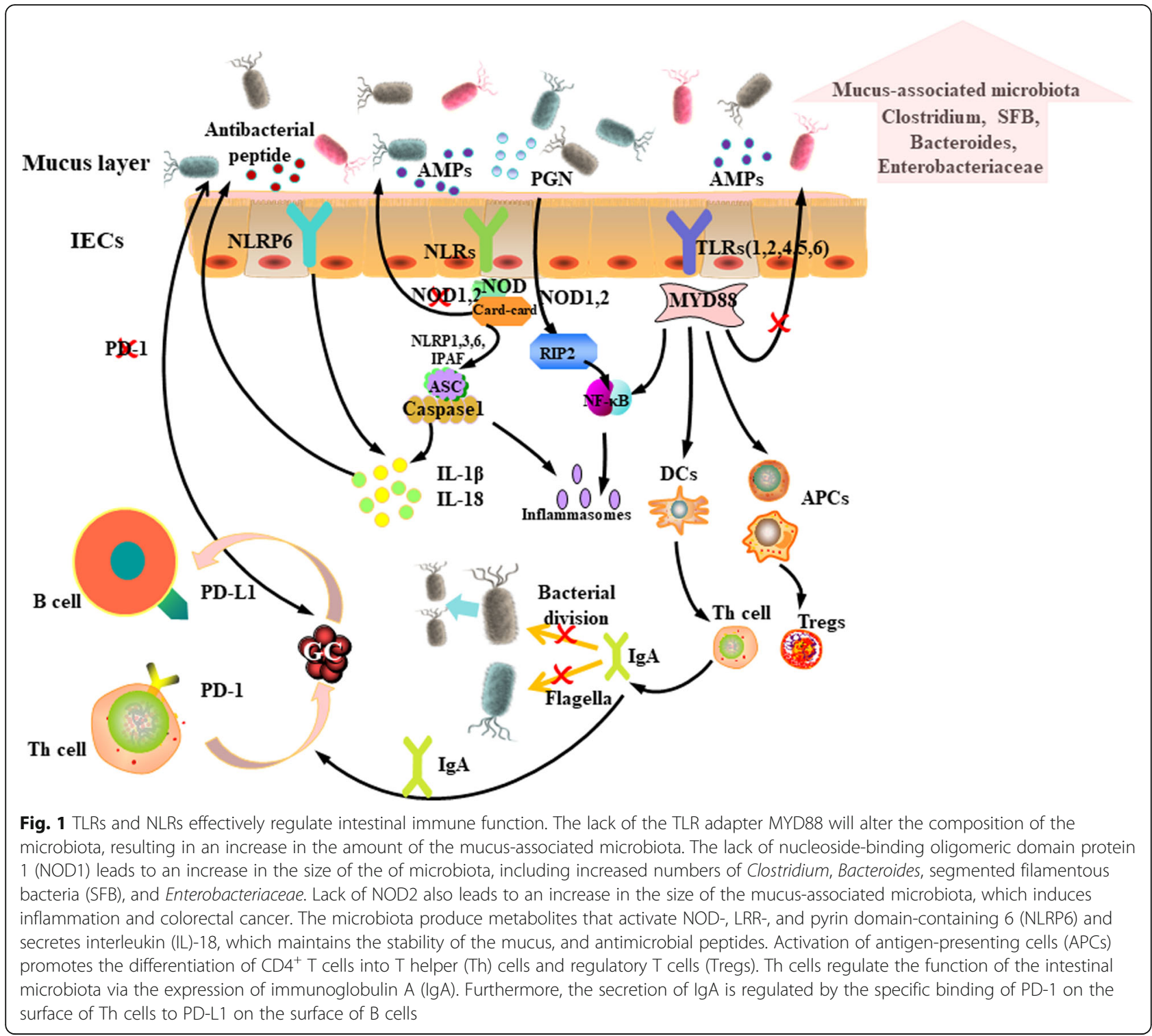

anthrax toxin [29]. NLRP3 is activated by ligands such as MDP and bacterial RNA, and forms a complex with the adapter apoptosis-associated speck-like protein containing a CARD (ASC) [23]. NLRP6 was discovered recently and is activated by the toxin released by Listeria monocytogenes [31]. IPAF is mainly activated by bacterial flagellin, which transmits the signal to the cytoplasm [32]. Then, NLRP1, NLRP3, NLRP6, and IPAF combine with ASC and recruit caspase-1 after forming inflammasomes in the cytoplasm, thereby promoting the release of IL-1 $\beta$, thus leading to an inflammatory response [28]. All of these factors contribute to the innate immune response to the microbiota, and they have a positive effect on tissue repair and tumor monitoring on the surface of the intestinal mucosa [23].
However, in the absence of NOD1, the size of the microbiota is increased, including increased numbers of symbiotic Clostridium, Bacteroides, segmented filamentous bacteria (SFB), and Enterobacteriaceae [33]. Similarly, the microbial population of mice lacking NOD2 also changed, characterized by an increase in the burden of the commensal microbiota and an increase in the proportion of the mucus-associated microbiota, resulting in intestinal inflammation and colorectal cancer in mice [34]. Similar to these observations in mice, a human NOD2 polymorphism is associated with Crohn's disease [35]. Interestingly, the expression of NOD2 depends on the existence of the commensal microbiota, thus suggesting a negative feedback relationship between the commensal microbiota and NOD2 [36]. In addition to NOD1 and NOD2, some NLR proteins assemble into a 
multiprotein complex that activates caspase 1 and further releases IL-1 $\beta$ and IL-18 [37]. NLRP6 proteins induce intestinal epithelial inflammatory body formation. NLRP6 has been shown to be critical in maintaining intestinal microbial homeostasis [38]. Mechanistically, symbiotic microbial-derived metabolites activate NLRP6-associated inflammatory corpuscle IL-18, which maintains mucus and antibacterial peptide stability, and controls the microbial composition [39, 40].

In the adaptive immune process, antigen-presenting cells (APCs) are activated by PAMPs and then transferred into mLNs to promote the differentiation of naive $\mathrm{T}$ cells into $\mathrm{CD}^{+}{ }^{+} \mathrm{T}$ cells [41]. $\mathrm{CD} 4^{+} \mathrm{T}$ cells differentiate into two subsets, $\mathrm{T}$ helper (Th) cells and regulatory $\mathrm{T}$ cells (Tregs). Th cells regulate the intestinal microbiota, especially microbial functions (such as flagella production) by selecting an appropriate immunoglobulin A (IgA) plasma cell bank [42]. IgA is crucial to maintain a symbiotic balance between the microbiota and the immune system. Interestingly, the most preferentially targeted microbiota for IgA is the one that proximally colonizes the mucosa and is associated with the potential pathogenicity of E. coli [43]. Studies on Shigella flexneri IgA antibodies have shown that IgA can induce the microbiota to fall into the mucous layer of the intestinal epithelium [44]. Then, IgA promotes its clearance by agglutination. IgA antibodies produced after oral inoculation with Salmonella typhimurium have been shown to inhibit and eliminate bacterially dividing daughter cells [45]. Although the reactivity of multi-reactive IgAs with flagellin is low, IgA might also limit bacterial movement by binding to bacterial flagellin [46]. In addition, the secretion of IgA is also regulated by the specific binding of programmed death receptor 1 (PD-1) expressed by Th cells to programmed death-ligand 1(PD-L1) on the surface of B cells [47]. IgAs produced in PD-1-deficient mice showed reduced bacterial binding capacity, leading to changes in the intestinal microbiota [48]. The changes' main feature is that the number of Bifidobacteria is reduced and the number of Enterobacteriaceae is increased [49]. Thus, PD-1 is vital to regulate the diversity of antibodies required to maintain a full mucosal barrier. Maruya et al. also found that PD-1 affects the kinetics of $B$ cells in the germinal center (GC) by regulating the quantity and nature of Th cells in Peyer's patches [47]. Studies have shown that compared with wild-type mice, the frequency of clone-related sequences (with the same VH-DH-JH and ligation) in PD-1deficient mice was reduced, resulting in impaired IgA plasma cell expansion in the GC [47]. Meanwhile, Kawamoto et al. found that the quality of IgA depends largely on the number of Th cells in Peyer's patches. Too many Th cells lead to dysregulation of IgA precursor cells in the GC, and the defect of PD-1 can lead to an increase in Th cells [48]. When PD-1-dependent checkpoints are missing, the intestinal microbiota crosses the mucosal barrier, inducing systemic GCs to produce autoreactive antibodies [48]. Therefore, the evidence indicates that PD-1 regulates the intestinal microbiota by appropriately selecting the IgA plasma cell sequence [48]. In addition, SFB can be directly attached to IECs to stimulate the secretion of serum amyloid A [50]. These proteins belong to the acute phase response protein family and respond to inflammation. Differentiation of Th17 cells and secretion of IL-17a were achieved under the induction of serum amyloid A [50,51]. Th17 cells are the differentiation of $\mathrm{CD}^{+} \mathrm{T}$ cells through transforming growth factor beta (TGF- $\beta$ ) and IL- 6 and play an important role in tumors. The significant feature of Th17 cells is their ability to produce IL-17. IL-17 has six family members (IL-17a-IL-17f) [52]. Among them, the expression levels of IL-17a and IL-17f are related to tumor angiogenesis [53]. The expression of IL-17a mRNA increases with the increase of tumor invasion and pathological stage. However, IL-17a has different promotion effects on tumor angiogenesis [54]. For example, in non-small cell carcinoma, IL-17a increases vascular proliferation by promoting the angiogenic chemokines $\mathrm{C}-\mathrm{X}-\mathrm{C}$ motif chemokine ligand (CXCL)1, 5, and 8. In human melanoma blood vessels, IL-17a upregulates the expression of vascular genes through an IL-6-dependent mechanism [54]. However, IL-17f has an inhibitory effect on tumor angiogenesis [55]. In colorectal cancer, overexpression of IL$17 \mathrm{f}$ reduces vascular endothelial growth factor (VEGF) levels, inhibits angiogenesis, thereby playing a protective role [55]. Therefore, these two cytokines form a balance in tumor growth, which is conducive to maintaining the body's immunity. However, there are conflicting opinions about the function of Th17 cells in tumor immunity, and that the fate of Th17 cells is regulated by many factors, including regulatory factors and intestinal bacterial antigens [56]. Among them, IL-23 can induce the expression of RUNX family transcription factor (RUNX)1 and RUNX3, which can maintain Th17 function for a long time by enhancing retinoic acid receptorassociated orphan receptor $\gamma \mathrm{t}$ (ROR $\gamma \mathrm{t}$ ) activity [57].

The lamina propria of the colon is rich in Tregs, which can express PD-1 and PD-L1. Moreover, the PD-1/PD$\mathrm{L} 1$ axis is thought to inhibit the response of $\mathrm{CD}_{4}^{+}$and $\mathrm{CD}^{+} \mathrm{T}$ cells $[58,59]$, maintaining immune tolerance to tumors and microbial antigens [60]. The inhibitory effect of Tregs on $\mathrm{CD}^{+}{ }^{+} \mathrm{T}$ cells is mediated by cytokines such as TGF- $\beta$ and IL-10 $[61,62]$ (Fig. 2). TGF- $\beta 1$ can trigger the release of IL-10 by Th1 cells and reduce the activity of effector T cells (Teffs) [63, 64]. The microbial metabolites short chain fatty acids (SCFAs) also exhibit a regulatory effect on immune factors. SCFAs activate signal transducer and activator of transcription 3 (STAT3) and 


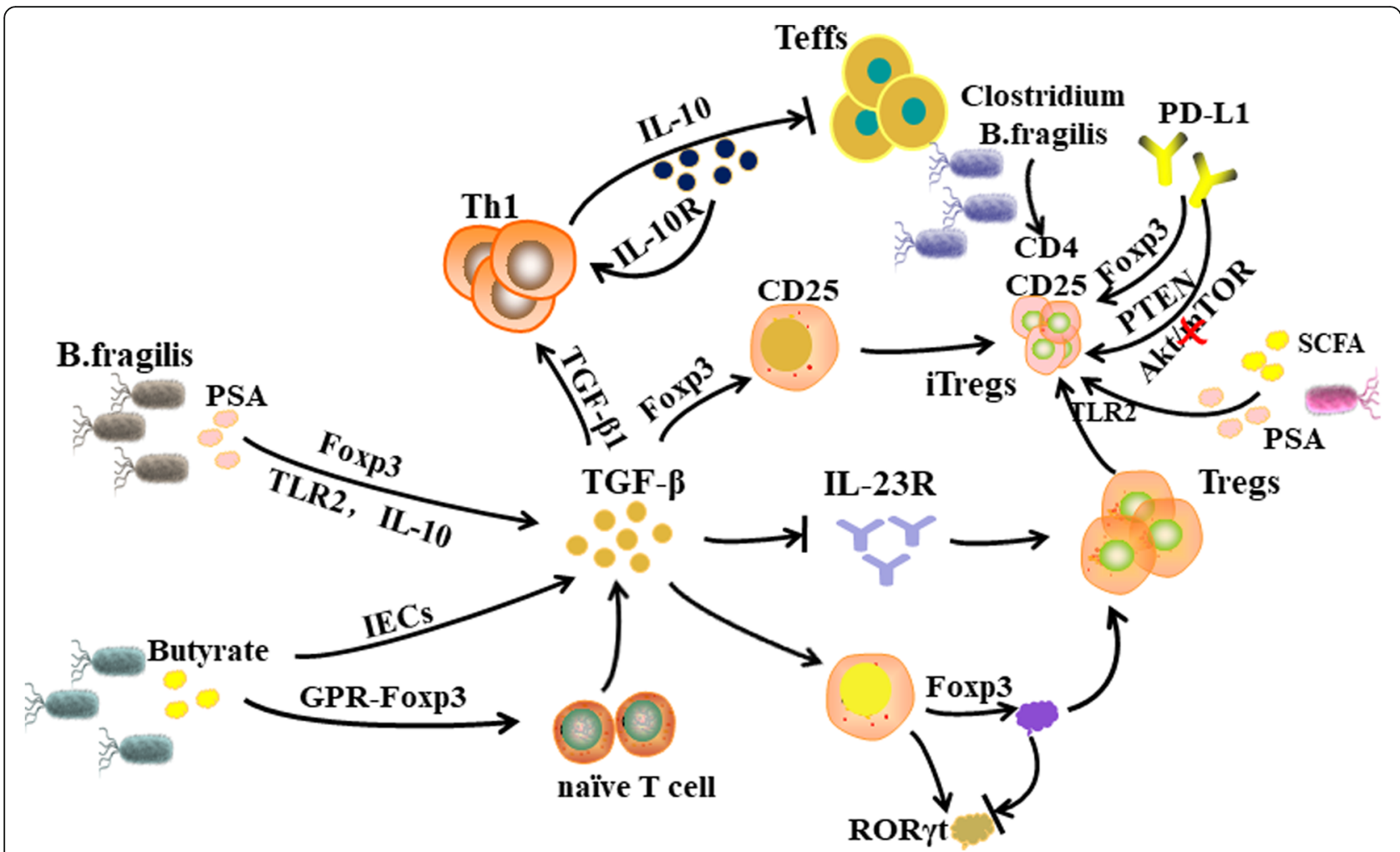

Fig. 2 The regulation of the microbiota in adaptive immunity. Bacteroides fragilis stimulates TLR2 on CD4 ${ }^{+} \mathrm{T}$ cells by producing polysaccharide A (PSA), thereby enhancing the expression of Forkhead Box P3 (Foxp3), IL-10, and TGF- $\beta$. Butyrate activates Foxp3 via a G protein-coupled receptor (GPCR), induces differentiation of Tregs, and inhibits anti-tumor immune responses. Butyrate also indirectly promotes Treg differentiation by inducing IECs to secrete TGF- $\beta$. High concentrations of TGF- $\beta$ inhibit the expression of IL-23R and promote the differentiation of Tregs. TGF- $\beta$ also induces RORyt to be expressed together with Foxp3 in CD4 ${ }^{+} T$ cells, which in turn inhibits RORyt, leading to differentiation of Tregs. Microbial metabolites SCFA and PSA can promote the proliferation of induced regulatory T cells (iTregs); however, too many iTregs infiltrating tumor tissue will weaken cancer immunity. PD-L1 can also promote the conversion of Tregs to iTregs by increasing the expression of Foxp3 and PTEN, or by inhibiting the Akt/mTOR pathway

mammalian target of rapamycin (mTOR) in Th1 cells, which in turn upregulate the transcription factor B lymphocytes to induce mature protein 1 (BLIMP-1) and induce IL-10 release [65]. Meanwhile, Cottrez et al. found that IL-10 can induce feedback regulation of TGF receptor expression and enhance the response of activated $\mathrm{T}$ cells to TGF- $\beta 1$ [66]. Forkhead box P3 (Foxp3) plays a key role in Treg development and immunosuppressive activity [67]. Mice with Foxp3 genetic defects have dysfunctional Tregs and develop an autoimmune disease similar to lupus [67]. TGF- $\beta$ induces the expression of Foxp3 in surrounding CD25 cells and converts them into $\mathrm{CD} 4{ }^{+} \mathrm{CD} 25^{+}$induced Tregs (iTregs) [59]. The expression of Foxp3 is controlled by the microbiota and microbial metabolites. B. fragilis promotes immune tolerance by producing the symbiotic factor polysaccharide A (PSA) [68]. PSA directly motivates TLR2 on $\mathrm{CD} 4^{+} \mathrm{T}$ cells, powerfully enhancing the expression of Foxp3, IL10 , and TGF- $\beta$ [69]. Microbial-derived butyrate inhibits the activity of histone deacetylase, which activates Foxp3 via a G-protein coupled receptor (GPCR) and promotes differentiation of naive $\mathrm{T}$ cells into Tregs, eliminating anti-tumor immune responses [70, 71]. Furthermore, butyrate is capable of indirectly promoting the differentiation of Tregs by inducing IECs to secrete TGF- $\beta[72$, 73]. High concentrations of TGF- $\beta$ prevent the expression of IL-23R and promote the differentiation of Tregs [74]. TGF- $\beta$ also induces the co-expression of ROR $\gamma \mathrm{t}$ and Foxp3 in $\mathrm{CD} 4^{+} \mathrm{T}$ cells. However, in vitro, a small proportion of Foxp3 induced by TGF- $\beta$ can have an inhibitory effect on ROR $\gamma \mathrm{t}$, and finally lead to the differentiation of Tregs [75]. IL-6, IL-21, and IL-23 can relieve the above inhibition [76]. Inducible regulatory $\mathrm{T}$ cells are a subset of intestinal Tregs that develop from $\mathrm{CD} 4{ }^{+}$Foxp3 naive $\mathrm{T}$ cells, depending on microbial antigenic stimulation [77]. Research by Atarashi and Round et al. showed that an increase in symbiotic Clostridium species and B. fragilis promoted intestinal iTregs [78]. Studies also showed that symbiotic microbiota, including most Clostridia, can produce SCFAs. Among them, butyrate is involved in the generation of iTregs by inhibiting pro-inflammatory factors and inducing Foxp3 
transcription [79]. B. fragilis strains expressing PSA can also mediate the generation of iTregs via TLR2 [79]. Francisco et al. also reported that PD-L1 induces the differentiation of iTregs by maintaining and increasing the expression of Foxp3 in iTregs [80]. PD-L1 inhibits the phosphatidylinositol-4,5-bisphosphate 3-kinase (PI3K)/ protein kinase B (Akt)/mTOR signaling cascade and upregulates phosphatase and tensin homolog (PTEN) to promote the transformation of iTregs [81]. However, iTregs infiltrate tumor tissue in large quantities, inhibiting effective tumor immunity [82]. The latest research shows that iTregs might be involved in the treatment of PD-1/PD-L1 blockade, and the PD-1/PD-L1 axis might also affect the differentiation and function of iTregs [83]. However, the complex relationship between them has not been fully determined. The above-mentioned process indicates that the microbiota and their metabolites are involved in the body's cancer immunity process.

\section{Tumor immunosuppression and immunotherapy}

The human immune system has always been the leading force for tumor suppression. The process requires coordination of cells, tissues, and the microenvironment to maintain overall immunity. A study found that the expression of immune checkpoints such as PD-1/PD-L1 and CTLA-4 plays a pivotal role in the balance and escape phase of cancer immunity [84]. In the tumor microenvironment, activation of the PD-1/PD-L1 pathway is beneficial to tumor immune escape [2]. PD-1 is expressed in a series of activated immune cells, including $\mathrm{T}$ cells, B cells, natural killer (NK) cells, and dendritic cells (DCs). PD-L1/PD-L2 is mainly expressed in APCs and tumor cells [85]. When PD-L1/PD-L2 on the surface of tumor cells binds to PD-1 on the surface of T cells, $\mathrm{T}$ cell activation is inhibited, resulting in apoptosis of tumor-specific T cells [86]. PD-L1 is expressed in various types of cancers, especially in non-small cell lung cancer (NSCLC), melanoma, gastric cancer, liver cancer, and leukemia tumors [87]. However, unlike PD-1/PDL1, CTLA-4 is expressed in specific Tregs and occurs in the early stages of $\mathrm{T}$ cell activation [88]. In contrast, PD1 is expressed in the late phase of $\mathrm{T}$ cell activation [89, 90]. From the crystal structure of CTLA-4/B7, they both have higher affinity [91]. Therefore, CTLA-4 recognizes B7 ligands on the surface of tumor cells and further inhibits $\mathrm{T}$ cell activation [92]. A large body of evidence indicates that Tregs expressing CTLA-4 have extracellular inhibition of traditional T cells [93]. Genetic studies have also shown that Tregs' expression of CTLA-4 is critical to control traditional $\mathrm{T}$ cell activation. Michella et al. also pointed out that CTLA-4 is a key effector used by Tregs to control the GC [93]. Mice lacking CTLA-4 will spontaneously develop $\mathrm{T}$ cell-driven lymphoproliferative syndrome, leading to early death [94].
Activation of checkpoint proteins on $\mathrm{T}$ lymphocytes helps tumors to escape immune surveillance. Therefore, the use of checkpoint inhibitors can reactivate the anticancer effects of $\mathrm{T}$ cells. Currently, two types of immunological checkpoint inhibitors (ICIs) that have been approved for clinical use by the FDA: Inhibitors of PD-1 or its ligand PD-L1 and inhibitors of CTLA-4 [95]. Research on ICIs has also made striking progress in determining the mechanism of checkpoints. Currently, common ICIs include anti-PD-1 (nivolumab and pembrolizumab) [96], anti-PD-L1 (durvalumab and atezolizumab) [97], and anti-CTLA-4 (ipilimumab) antibodies [98]. Many studies have shown that nivolumab in patients with solid tumors (including advanced melanoma) has good anti-tumor activity and safety [99]. Another clinical study reported the results of a randomized, double-blind, phase III trial, which showed that nivolumab improves overall survival in patients with advanced melanoma without B-Raf proto-oncogene, serine/threonine kinase (BRAF) mutations compared with dacarbazine [100]. In addition, first-line pembrolizumab monotherapy could improve overall survival and progression-free survival in patients with untreated metastatic NSCLC, with a PD-L1 tumor proportional score (TPS) of 50\% or higher [101]. Although PD-1 ICIs have achieved unparalleled success among similar drugs, because of individual differences in drug resistance of patients, some patients do not gain much benefit from ICIs [102]. The goal of developing combination therapy is to help patients with cancer who benefit less from monotherapy. Hodi et al. showed that first-line nivolumab combined with ipilimumab or nivolumab alone in patients with advanced melanoma, regardless of BRAF mutation status, could obtain long-lasting, sustained clinical benefits [103]. The joint treatment was more likely to improve survival outcomes than treatment with nivolumab alone [103]. Rozeman et al. also determined the optimal dose tolerated in a trial in which ipilimumab combined with nivolumab was used to treat macroscopic melanoma (OpACIN-neo) in the naked eye (ipilimumab $1 \mathrm{mg} / \mathrm{kg}+$ nivolumab $3 \mathrm{mg} / \mathrm{kg}$, two cycles) [104]. Some clinical trials have achieved considerable effects, and many patients are pinning their hopes on ICIs.

\section{The potential of intestinal microbiota in cancer immunotherapy}

Unfortunately, despite patients' expectations, a large proportion of patients with cancer are resistant to ICIs or produce only a heterogeneous, transient response [105]. Patients might have multiple complications that could prevent the safety of ICIs from being guaranteed. A meta-analysis of the use of ICIs suggested that the combination of nivolumab and ipilimumab might result in a higher risk of full-scale immune-related endocrine 
disease than ipilimumab or nivolumab alone [106]. Another meta-analysis acknowledged that combination therapy has a high incidence of adverse reactions and might even lead to treatment interruption [107]. Identifying more valuable immune checkpoints or increasing the sensitivity and persistence of ICIs to known checkpoints is the focus of our future research.

The human microbial community is an organ with endless potential. It not only regulates the body's tissue metabolism, but also participates in the body's immune regulation. It plays an important role in diseases such as gastrointestinal cancer and diabetes [18]. The intestinal microbiota has gradually emerged as a potent force in the process of cancer immunotherapy [108]. Initially, researchers were unsure whether the symbiotic microbiota affected the body's spontaneous immune response, thus affecting the therapeutic activity of ICIs interventions. To investigate this correlation, Sivan et al. selected mice with melanoma with the same genotypes from different laboratories (From TAC and JAX), and noted the melanoma of TAC mice was more severe than that of JAX mice [109]. After feeding under the same conditions, the researchers found that tumors in TAC mice were suppressed. After feeding with a fecal suspension of two mice, it was confirmed that the commensal microbiota of JAX mice had an anti-tumor effect [110]. Finally, the researchers used JAX mouse fecal suspensions in combination with PD-L1 ICIs. Their anti-tumor effect was significantly better than that of ICIs alone, including significantly delayed tumor growth and increased tumorspecific T cell responses [109]. This experiment clarified the function of the intestinal microbiota to optimize and enhance the efficacy of ICIs, suggesting that it could be used as an adjunct to ICI treatment.

Chaput et al. also predicted the clinical response and colitis occurrence in patients with metastatic melanoma treated with ipilimumab via their baseline intestinal microbiota [111]. Based on the study data, they speculated that the ipilimumab-induced anti-cancer response and the colitis caused by the formulation might depend on the patient's intestinal microbiota [111]. This prospective study facilitated the identification of potentially beneficial and harmful microbiota, which would allow control of the adverse risks that patients may face [111]. In fact, depending on the composition of the patient's intestinal microbiota, PD-1 blockers (R) and nonresponders (NR) could be stratified using the RECIST 1.1 standard [112]. Derosa et al. performed fecal microbial transplantation (FMT) from the feces of $\mathrm{R}$ patients or NR patients in sterile or antibiotic treated mice, respectively [49]. The fecal immune response of $R$ patients to tumors was stronger than that of NR patients. Subsequently, mice immunized with feces from NR patients were supplemented with Akkermansia muciniphila to restore anti-cancer activity against PD- 1 treatment [49, 113]. Increasing numbers of parallel studies have further confirmed the association of intestinal microbiota with ICIs [114]. However, the intestinal microbiota is rich in species, and there remains an urgent to identify a group that has specific effects on ICIs. In a study using metagenomic shotgun sequencing and unbiased metabolomic profiling to determine the efficacy of intestinal microbiota and ICIs in the treatment of patients with melanoma, researchers analyzed the patient's stool to find the difference between the intestinal metabolites from the responder and the disease-promoting population [115]. The study found that the composition of the host intestinal microbiota was the main factor determining the response to ICIs, which was consistent with the results of preclinical mouse model studies. In addition, the results showed that sterile or antibiotic-treated mice did not respond to immunotherapy, and Bacteroides was required for an anti-CTLA-4 response [115]. Vetizou and colleagues also revealed that antibiotic-treated or aseptically treated mice do not respond to CTLA-4 blockade. The team revealed that $\mathrm{T}$ cells are involved in the specific response of Bacteroides thetaiotaomicron or B. fragilis and the efficacy of CTLA-4 blockers [116]. Further studies have found that the anti-cancer effect of CTLA-4 blockers depends on different Bacteroides species [116]. In that study, the Bacteroides were divided into three clusters, A, B, and C, based on the fecal bacteria clustering algorithm. Then, patients with melanoma were treated with ipilimumab and found to be more likely to fall into cluster $C[117,118]$. Sequencing of the 16 S ribosomal RNA (rRNA) gene amplicon in feces showed that the therapeutic effect of CTLA-4 ICIs was dependent on cluster C, but not clusters A and B [119]. This was mainly because the microbiota of cluster $\mathrm{C}$ mainly comprises immunogenic Bacteroides, which can restore antiCTLA-4 monoclonal antibody (mAb) efficacy. Clusters $\mathrm{A}$ and $\mathrm{B}$ comprise tolerant Bacteroides, which can produce complete resistance to treatment $[119,120]$. This finding indicated that patients showing resistance or no response might benefit from FMT treatment.

During the same period, Sivan discovered that the control effect of oral Bifidobacterium on tumors was the same as that of PD-L1 ICIs using 16S rRNA sequencing, and determined the anti-tumor effects of Bifidobacterium, especially Bifidobacterium breve, Bifidobacterium longum, and Bifidobacterium adolescentis [109, 121]. Oral administration of Bifidobacterium increased the infiltration of $\mathrm{CD}^{+} \mathrm{T}$ cells and enhanced the production of interferon gamma (IFN- $\gamma$ ). In addition, Bifidobacterium promoted intratumoral DC activation to improve the underlying tumor environment and anti-PD-L1 efficacy [109]. Interestingly, a recent study by Matson et al. examined fecal samples collected from patients with 
metastatic melanoma before immunotherapy [122]. They found that members of the microbiota such as, Bifidobacteria longum and Collinsella aerofaciens were enriched in response to anti-PD-1 immunotherapy [122]. Another study showed that Enterococcus faecium is abundant in the microbiota and has a synergistic effect with Bifidobacteria in the anti-cancer process [122]. Several other studies have confirmed that the intestinal microbiota could be a new force in anti-immunization checkpoint therapy $[122,123]$. Based on the consensus of these studies, we concluded see that patients with good intestinal microbiota have an enhanced anti-tumor immune response by improving their effector $\mathrm{T}$ cell function in the tumor microenvironment. In contrast, patients with poor intestinal microbiota have poorer anti-tumor immune responses because of limited myeloid infiltration and reduced antigen presentation. It could be said that the microbiota controls the cancer immune setting of individuals with cancer, and it may be feasible to manipulate the intestinal ecosystem to bypass resistance to ICIs [113].

\section{A powerful auxiliary role of microbiota in cancer immunotherapy}

It has become clear that the intestinal microbiota plays a vital role in the process of cancer immunotherapy. The intestinal microbiota mainly promotes cancer immunotherapy and optimizes the use of ICIs from the following aspects.

When PRRs such as TLRs and NODs recognize PAMPs from the microbiota, a local intestinal immune response is initiated. PAMPs promote the maturation of DCs through interaction with PRRs. Bifidobacteria are capable of inducing transcription of DC genes and promoting their maturation [109]. This process facilitates the recruitment and activation of lymphocytes and enhances the efficiency of antigen presentation. In addition, the threshold for the activation of DCs by Bifidobacteria is downregulated, meaning that the concentration of antigen required to initiate $\mathrm{T}$ cells is reduced, and sensitivity is increased. Studies have shown that at lower antigen concentrations, DCs upregulate IFN- $\gamma$ levels, initiate the proliferation of tumor-specific $\mathrm{CD} 8^{+} \mathrm{T}$ cells, and produce synergistic anti-tumor effects with ICIs $[124,125]$ (Table 1). This process promotes activation of DCs in the spleen and tumors, improving basal tumor control and anti-PD-L1 efficacy (Fig. 3). APCs can also detect the intestinal microbiota without microbiota translocation $[126,127]$. The microbiota-mediated immune response not only activates an inflammatory response in the mucosa, but also induces the differentiation of pathogenic Th17 (pTh17) and Th1 cells in the secondary immune organs [128].

B. fragilis activates Th1 cells to cross-react with bacterial antigens and new tumor antigens, enhancing the efficacy of anti-CTLA-4 [129]. At the same time, colonization of germ free mice with $B$. fragilis and $B$. cepacia reduced the toxicity induced by anti-CTLA-4 $\mathrm{mAb}$ [116]. This might be related to the ability of $B$. fragilis to promote Treg proliferation. Monoclonalization by $B$. fragilis and Bifidobacteria also promotes the conversion of $\mathrm{CD} 4^{+} \mathrm{T}$ cells to Tregs [130]. When the IL-10 signal is blocked, the disturbance of the intestinal mucosal barrier is further increased. This might be caused by intestinal toxicity caused by pTh17 cells, such as colitis [131]. It is worth noting that the efficacy of oral B. fragilis is associated with Th1 immune responses induced in lymph nodes and DC maturation in the tumor bed [132]. Among them, plasma cell-like DCs (pDCs) activate lamina propria $\mathrm{DCs}$, which can promote the

Table 1 Regulation of intestinal microbiota in cancer immunotherapy

\begin{tabular}{|c|c|c|}
\hline $\begin{array}{l}\text { Microbiota } \\
\text { (or products) }\end{array}$ & Immune regulation & Impact on cancer immunotherapy \\
\hline Bifidobacteria & $\begin{array}{l}\text { Promoting maturation of DCs } \\
\text { Activating lymphocytes } \\
\text { Upregulating IFN- } \gamma \text { and increasing pro-inflammatory cytokine } \\
\text { Initiating the proliferation of tumor-specific } C D 8^{+} T \text { cells }\end{array}$ & Enhancing PD-1 blockade \\
\hline B. fragilis & $\begin{array}{l}\text { Activating Th1 cells } \\
\text { Promoting Tregs proliferation } \\
\text { Promoting maturation of DCs }\end{array}$ & Enhancing CTLA-4 blockade \\
\hline A. muciniphila & Increasing $\mathrm{CXCR} 3^{+} \mathrm{CCR}^{+} \mathrm{CD}^{+} \mathrm{T}$ cells & Enhancing PD-1 blockade \\
\hline $\begin{array}{l}\text { Escherichia } \\
\text { Clostridium }\end{array}$ & Inducing the differentiation of Tregs and inhibiting inflammation & Enhancing CTLA-4 blockade \\
\hline Faecalibacterium & $\begin{array}{l}\text { Promoting the proliferation of } \mathrm{CD}^{+} \text {or } \mathrm{CD}^{+} \mathrm{T} \text { cells } \\
\text { Promoting the production of Tregs and upregulating the expression of ICOS }\end{array}$ & $\begin{array}{l}\text { Enhancing PD-1 blockade } \\
\text { Enhancing CTLA-4 blockade }\end{array}$ \\
\hline Bacteroides & $\begin{array}{l}\text { Upregulating the system's MDSC and Tregs } \\
\text { Causing a systemic inflammatory response through the TLR-NF } \\
\text { inflammatory pathway }\end{array}$ & $\begin{array}{l}\text { Impeding PD-1 blockade } \\
\text { Impeding CTLA-4 blockade }\end{array}$ \\
\hline microbial-derived SCFAs & Promoting the differentiation of Tregs & Enhancing CTLA-4 blockade \\
\hline
\end{tabular}




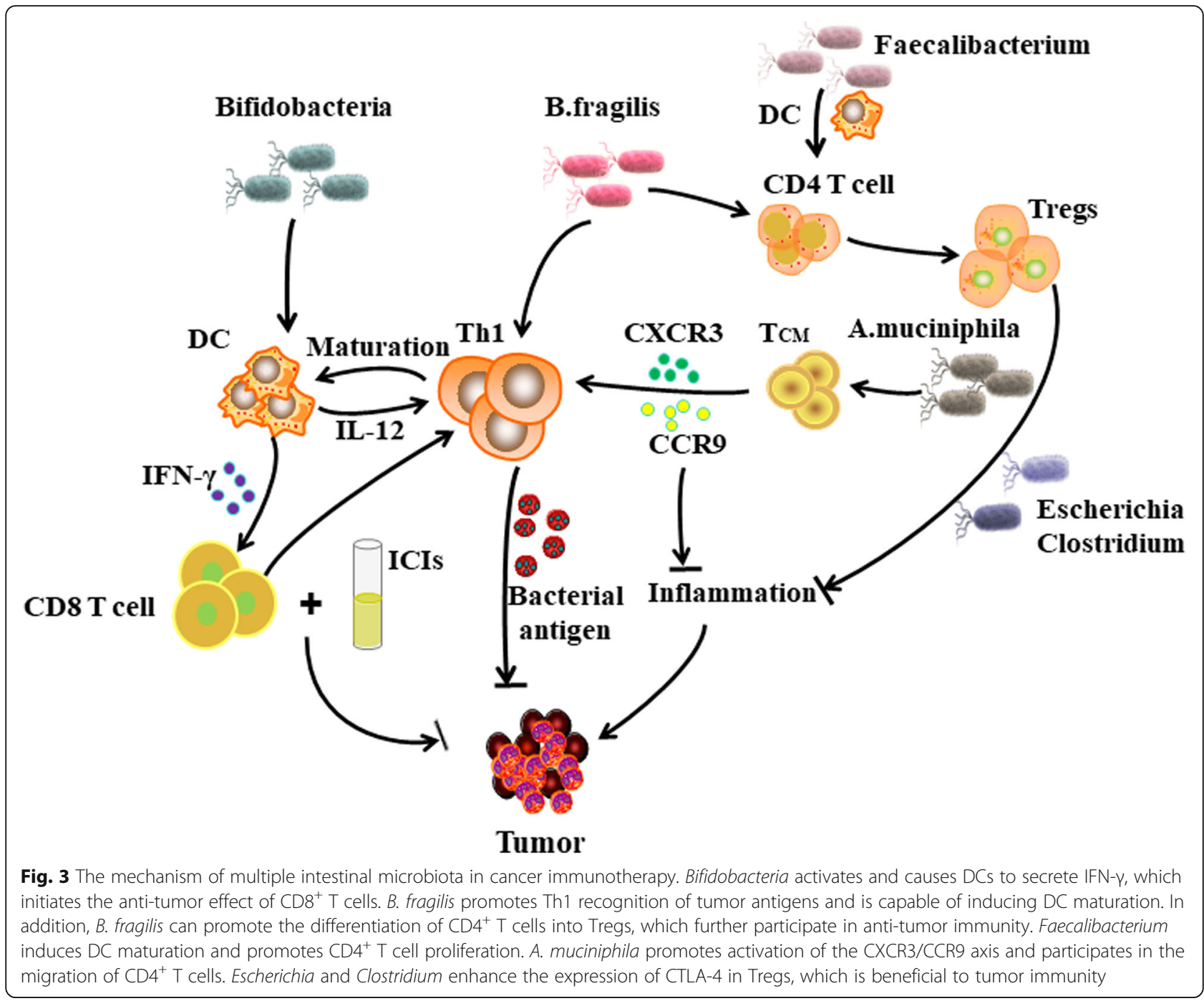

absorption of B. fragilis [133]. Alternatively, absorption of soluble bacterial products by DCs promotes DC maturation and the production of IL-12, which in turn allows for the initiation of T cells (such as Th1) [134]. IL12 might be produced as a result of $B$. fragilis mobilizing the lamina propria of $\mathrm{CD}_{11 \mathrm{~b}^{+}} \mathrm{DC}$ [135]. These processes might be involved in the anti-tumor immune responses by $\mathrm{T}$ cells homologous to tumor antigens or cross-reactive bacterial antigens.

Colonization by the acidophilic Akkermansia muciniphila and Enterococcus hirae is associated with the appearance of $\mathrm{CD}^{+}$central memory $\mathrm{T}$ cells $\left(\mathrm{T}_{\mathrm{CMs}}\right)$ in tumors and the coding of mLNs [113]. C-X-C motif chemokine receptor 3 (CXCR3)/ C-C motif chemokine receptor 9 (CCR9) are chemokine receptors expressed by $\mathrm{T}_{\mathrm{CMs}}$ [136]. The CXCR3 and CCR9/CCL25 axes are associated with progression free survival (PFS) and overall survival (OS) prolongation in some patients with advanced cancer [137]. CXCR3 is also involved in enlisting Th1 cells to inflammatory lesions. The CCR9/ CCL25 axis is involved in $\mathrm{T}$ cell chemotactic migration, and Th cells expressing CCR9 exhibit site specificity during inflammation $[138,139]$. Some data suggest that $\mathrm{T}$ cell epitopes are shared between the microbiota and tumor cells [113]. Under this model, $\mathrm{T}$ cells might exert anti-tumor effects through $\mathrm{CD} 4^{+}$ $\mathrm{T}$ cell $\mathrm{CD}^{+} \mathrm{T}$ cells in response to cross-reactivity of bacterial antigens [140]. Balachandran et al. found that $\mathrm{T}$ cell clones around and within tumors are specific for both new antigens and predict their crossreactivity with microbial epitopes [141]. Therefore, microbiota has a certain promotion effect on the blocking effect of PD-1.

In addition, immune cell detection showed that intestinal Faecalibacterium increased the role of DC and other APCs to promote the proliferation of $\mathrm{CD} 4^{+}$ 
or $\mathrm{CD}^{+} \mathrm{T}$ cells, which is conducive to enhancing the blocking effect of PD-1 [142]. Furthermore, Faecalibacterium enhances the blocking effect of CTLA-4 by promoting the production of Tregs and upregulating the expression of inducible T cell costimulatory (ICOS) [143]. However, some members of the microbiota have antagonistic effects on ICIs. Bacteroides blocked PD-1 blockade by upregulating the system's myeloid-derived suppressor cells (MDSCs) and Tregs [144]. Bacteroides can also cause a systemic inflammatory response through the TLR-NF inflammatory pathway, hindering the blocking effect of CTLA-4 [145].

The intestinal microbiota and its metabolites are beneficial to activate Tregs [146]. SCFAs are microbial metabolites that affect many characteristics of host immunity [147]. Intestinal microbial-derived SCFAs, such as butyrate and propionate, promote the differentiation of Tregs and increase the size of the Tregs pool by increasing the acetylation level of histone $\mathrm{H} 3$ in the Foxp3 promoter region and the conserved non-coding region [148-150]. The high expression of CTLA-4 in Tregs means that the status of Tregs at baseline is critical to determine CTLA-4 blockade [151]. Some members of the microbiota, such as Escherichia and Clostridium, can induce differentiation of Tregs and inhibit the occurrence of inflammation. It is speculated that anti-inflammatory microbiota and SCFAs induce proliferation and differentiation of Tregs, resulting in higher levels of CTLA-4 [150]. Although elevated CTLA-4 levels are beneficial for tumors to evade immune surveillance, they can increase sensitivity to CTLA-4 blockade by relieving immunosuppression of the gut and tumor tissues [152]. The involvement of Tregs is more pronounced in the blocking of CTLA-4 than in PD-1 blockade. Therefore, theoretically, patients receiving CTLA-4 blockade are more likely to benefit from enhanced $\mathrm{T}$ cells.

These underlying mechanisms might contribute to microbial mediation of anti-tumor immune regulation in the context of intestinal inflammation, such as chemotherapy drugs that cause mucositis, or anti-CTLA-4 treatment $[153,154]$. Thus, the intestinal microbiota has been recognized as a major force in the process of cancer immunity.

\section{The future of the intestinal microbiota in cancer immunotherapy}

As a result of ongoing research, we predict that the intestinal microbiota will gradually occupy an increasingly prominent position in cancer immunotherapy. Currently, the mechanism of the effects of the intestinal microbiota in cancer immunotherapy is not well understood; however, some ongoing clinical trials will help to reveal the potential of the intestinal microbiota in tumor development and cancer immunotherapy. We have summarized the clinical trials investigating the intestinal microbiota involvement in cancer immunotherapy in recent years (Table 2). Meanwhile, we also compiled a schematic diagram showing the enrichment of the intestinal microbiota in the process of cancer immunotherapy (Fig. 4). This evidence will provide a good reference for the effectiveness of the intestinal microbiota in the immunotherapy process.

The development of these clinical trials will remove obstacles for the use of the intestinal microbiota to optimize and assist immunotherapy using ICIs. First, the intestinal microbiota can reduce complications during cancer immunotherapy. Currently, there are some complications associated with the use of ICIs. The most common toxic response when using ICIs is associated colitis. The cause of the disease is obscure. Interestingly, the lactic acid bacteria Lactobacillus reuteri can completely eliminate ICIsassociated colitis, and improve weight loss and inflammation [157]. The protective effect of $L$. reuteri might be related to the decrease in lymphocyte distribution [158]. Second, the intestinal microbiota enhances the nutritional absorption capacity of patients with cancer and enhances their anti-tumor ability. The emergence of tumor micro-ecological immune nutrition has further paved the way for the development of the microbiota as tool in cancer immunotherapy [159]. The main function of the intestinal microbiota is to help the host to digest and metabolize food [160]. However, in patients with cancer, their intestinal function is often destroyed, and they find it difficult to utilize the nutrition in the diet. The addition of micro-ecological preparations to parenteral nutrition could effectively interfere with the environment of intestinal disorders, reestablish a good tumor microenvironment, and play a role in anti-tumor immunity [161]. Third, microbiota research is expected to lead to the design of a vaccine against tumors. A recent microbial-based cancer vaccine has shown its utility [162]. This cancer vaccine prevents the growth of squamous cell carcinoma expressing epidermal growth factor receptor (EGFR) vIII and induces EGFR vIII-specific cellular immunity [162]. This work is exciting for the study of anti-tumor immunity, and represents a new breakthrough in the design of the microbiota. Fourth, FMT is expected to be the most direct biooptimization tool for cancer immunotherapy. FMT is a popular and significant technology that has been used clinically to treat recurrent Clostridium difficile infections [163]. 
Table 2 FDA-approved trials of microbial-related immunotherapy

\begin{tabular}{|c|c|c|c|c|c|}
\hline NCT Number & Title & Status & Conditions & Interventions & Phases \\
\hline NCT02960282 & $\begin{array}{l}\text { Gut Microbiome in Fecal } \\
\text { Samples From Patients } \\
\text { With Metastatic Cancer } \\
\text { Undergoing Chemotherapy } \\
\text { or Immunotherapy }\end{array}$ & Recruiting & $\begin{array}{l}\text { Metastatic Carcinoma } \\
\text { Stage IV/IVA/IVB } \\
\text { Colorectal Cancer }\end{array}$ & $\begin{array}{l}\text { Procedure: Biospecimen } \\
\text { Collection } \\
\text { Other: Laboratory } \\
\text { Biomarker Analysis }\end{array}$ & \\
\hline NCT03341143 & $\begin{array}{l}\text { Fecal Microbiota Transplant } \\
\text { (FMT) in Melanoma Patients }\end{array}$ & Recruiting & Melanoma & FMT with Pembrolizumab & Phase 2 \\
\hline NCT03353402 & $\begin{array}{l}\text { Fecal Microbiota Transplantation } \\
\text { (FMT) in Metastatic Melanoma } \\
\text { Patients Who Failed } \\
\text { Immunotherapy }\end{array}$ & Recruiting & $\begin{array}{l}\text { Melanoma Stage IV } \\
\text { Unresectable Stage III Melanoma }\end{array}$ & FMT & Phase 1 \\
\hline NCT03370861 & $\begin{array}{l}\text { How Microbes and Metabolism } \\
\text { May Predict Skin Cancer } \\
\text { Immunotherapy Outcomes }\end{array}$ & Recruiting & $\begin{array}{l}\text { Skin Cancer|Melanoma } \\
\text { Merkel Cell Carcinoma } \\
\text { Squamous Cell Carcinoma } \\
\text { of the Skin Basal Cell } \\
\text { Carcinoma }\end{array}$ & Immunotherapy & \\
\hline NCT03383107 & $\begin{array}{l}\text { Effect of Radiotherapy } \\
\text { Variables on Circulating } \\
\text { Effectors of Immune } \\
\text { Response and Local } \\
\text { Microbiome }\end{array}$ & Recruiting & Breast Cancer|Prostate Cancer & & \\
\hline NCT03557749 & $\begin{array}{l}\text { Monitoring of Immune and } \\
\text { Microbial Reconstitution } \\
\text { in }(\mathrm{HCT}) \text { and Novel } \\
\text { Immunotherapies }\end{array}$ & Recruiting & $\begin{array}{l}\text { Immune and Microbial } \\
\text { Reconstitution Recurrent } \\
\text { Malignant Cell Therapy/ } \\
\text { Immunotherapy Patients }\end{array}$ & $\begin{array}{l}\text { Diagnostic Test: Blood Sample/ } \\
\text { Stool Sample Gastrointestinal } \\
\text { biopsy } \times 2-4 / \text { Apheresis } \\
\text { Product/Final cellular product }\end{array}$ & \\
\hline NCT03595683 & $\begin{array}{l}\text { Pembrolizumab and EDP1503 } \\
\text { in Advanced Melanoma }\end{array}$ & Recruiting & Melanoma (Skin)|Melanoma & $\begin{array}{l}\text { Pembrolizumab } \\
\text { Biological: EDP1503 }\end{array}$ & Phase 2 \\
\hline NCT03643289 & $\begin{array}{l}\text { Predicting Response to } \\
\text { Immunotherapy for Melanoma } \\
\text { With Gut Microbiome and } \\
\text { Metabolomics }\end{array}$ & Recruiting & Melanoma (Skin) & & \\
\hline NCT03686202 & $\begin{array}{l}\text { Feasibility Study of Microbial } \\
\text { Ecosystem Therapeutics (MET-4) } \\
\text { to Evaluate Effects of Fecal } \\
\text { Microbiome in Patients on } \\
\text { Immunotherapy }\end{array}$ & Recruiting & All Solid Tumors & Biological: MET-4 & Early Phase 1 \\
\hline NCT03772899 & $\begin{array}{l}\text { Fecal Microbial Transplantation } \\
\text { in Combination With } \\
\text { Immunotherapy in Melanoma } \\
\text { Patients (MIMic) }\end{array}$ & Recruiting & Melanoma & FMT & Phase 1 \\
\hline NCT03797170 & $\begin{array}{l}\text { Design of New Personalized } \\
\text { Therapeutic Approaches for } \\
\text { Diffuse Large B-cell Lymphoma }\end{array}$ & Recruiting & $\begin{array}{l}\text { Diffuse Large B Cell } \\
\text { Lymphoma }\end{array}$ & Gut microbiota samples & \\
\hline NCT03817125 & $\begin{array}{l}\text { Melanoma Checkpoint and } \\
\text { Gut Microbiome Alteration } \\
\text { With Microbiome Intervention }\end{array}$ & Recruiting & Metastatic Melanoma & $\begin{array}{l}\text { Placebo for antibiotic } \\
\text { Vancomycin pretreatment } \\
\text { Nivolumab/SER-401/SER-401 }\end{array}$ & Phase 1 \\
\hline NCT03891979 & $\begin{array}{l}\text { Gut Microbiome Modulation to } \\
\text { Enable Efficacy of Checkpoint- } \\
\text { based Immunotherapy in } \\
\text { Pancreatic Adenocarcinoma }\end{array}$ & Not yet recruiting & Pancreatic Cancer & $\begin{array}{l}\text { Antibiotics and } \\
\text { Pembrolizumab }\end{array}$ & Phase 4 \\
\hline
\end{tabular}

As microbiota research shifts from correlation studies to mechanistic studies, the activity of specific microorganisms and their products will be validated in areas such as inflammatory bowel disease and cancer. Although FMT is still in its infancy in clinical trials of cancer, it still represents a milestone in cancer therapy research. For example, clinical trial NCT03353402 proposes to change the intestinal microbiota of patients with melanoma who have failed immunotherapy using FMT. Another clinical trial (NCT03341143) is investigating the feasibility of FMT in patients with melanoma who are resistant to PD-1 ICIs. Furthermore, safety studies using FMT in combination with immunotherapy (pembrolizumab or nivolumab) are also being tested in a clinical trial (NCT03772899). These clinical trials will further examine the position of FMT in cancer immunotherapy. 


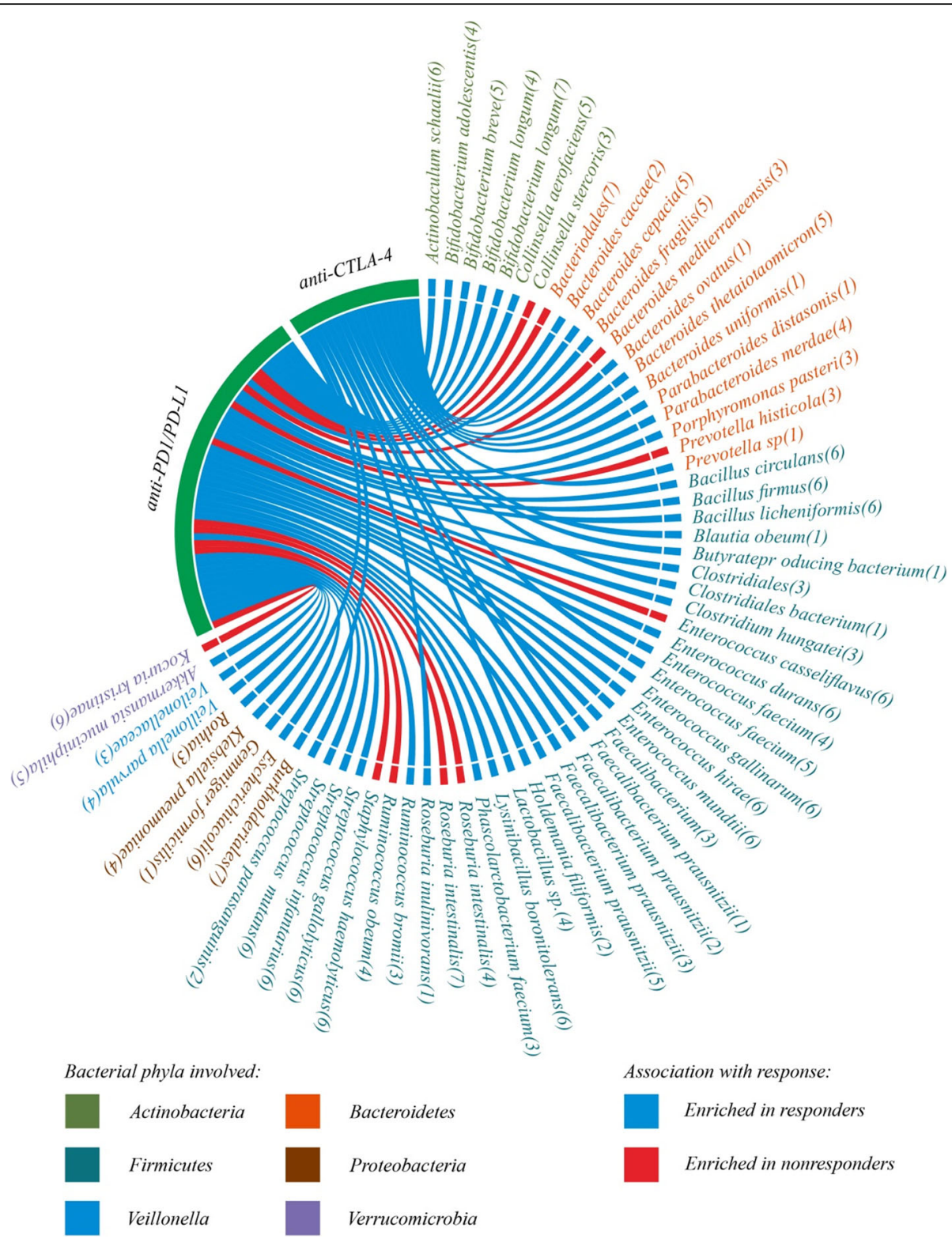

Fig. 4 Differences in microbial enrichment during immunotherapy. The Circos diagram illustrates the different effects of different members of the microbiota in the treatment of ICls. Blue bands represent members of the microbiota that are enriched during the treatment of effective ICls. Red bands represent members of the microbiota that are enriched during the treatment of ineffective ICls. The numbers in parentheses are the source of the reference. (1) Chaput et al. [111] (2) Frankel et al. [115] (3) Gopalakrishnan et al. [123] (4) Matson et al. [122] (5) Routy et al. [155] (6) Routy et al. [113]. (7) Temraz et al. [156]

\section{Conclusion}

The intestinal microbiota has shown its potential as a major force in cancer immunotherapy. It not only participates in regulating the body's immunity, but also assists in optimizing the therapeutic effects of ICIs. At the same time, as a tool for adjuvant therapy and the comprehensive evaluation of patients' benefits, the targeted benefits of microbiota will gradually become clear, which could be considered in combination with FMT. Although the mechanisms of the effects of the microbiota are unclear, emerging technologies such as microbiome-wide association study (MWAS) and 16S rRNA sequencing will provide clarity in the near future. Not only do we need to fully understand how the microbiota regulates cancer immunotherapy in the context of preclinical models and clinical trials, but more importantly, we need to use these data to develop immunotherapeutic probiotics to help improve the efficacy of immunotherapy in patients. 


\section{Abbreviations}

AMPs: Antimicrobial peptides; APCs: Antigen-presenting cells; Blimp-1: B lymphocytes to induce mature protein 1; CTLA-4: Cytotoxic T lymphocyte antigen 4; EGFR: Epidermal growth factor receptor; DAMPs: Damage-related molecular patterns; FMT: Fecal microbial transplantation; GPCR: G-protein coupled receptor; ICls: Immunological checkpoint inhibitors; IECs: Intestinal epithelial cells; mLNs: Mesenteric lymph nodes; MYD88: Myeloid differentiation of primary response protein 88; NOD1: Nucleoside-binding oligomeric domain protein 1; NLRs: NOD-like receptors; NLRP6: NOD-, LRR-, and pyrin domain-containing 6; NSCLC: Non-small cell lung cancer; pTh17: Pathogenic Th17; PD-1/PD-L1: Programmed death receptor 1/ programmed death-ligand 1; PRRs: Pattern recognition receptors; PAMPs: Pathogen-associated molecular patterns; PTEN: Phosphatase and tensin homolog; RORyt: Receptor-associated orphan receptor $\gamma t$; TPS: Tumor proportional score; TLRs: Toll-like receptors

\section{Acknowledgements}

We thank to Dikan Wu his help with the writing process.

\section{Authors' contributions}

ZD and JZ drafted the manuscript. QW and CS researched the literature and drafted figures. HF, ZL, and $C L$ counted and plotted the Circos diagram and tables. DT and DW critically revised the article for important intellectual content. All authors read and approved the final manuscript.

\section{Funding}

This work was supported by grants from the Training Project of Key Talents of Youth Medicine in Jiangsu province, China [No. QNRC2016330], the Key disease standardization diagnosis and treatment project in Jiangsu province [BE2015664], the Academic Science and Technology Innovation Fund for College Students [No. $\times 20180714]$, the Social Development-Health Care Project of Yangzhou, Jiangsu Province [No. YZ2018087], and High-level talent "six one projects" top talent scientific research project of Jiangsu Province [No. LGY2019034]. The funding bodies had no role in the design of the study; in the collection, analysis, and interpretation of the data; and in writing the manuscript.

\section{Availability of data and materials}

Not applicable.

\section{Ethics approval and consent to participate}

Not applicable.

\section{Consent for publication}

Not applicable.

\section{Competing interests}

The authors declare that there is no conflict of interest.

\section{Author details}

${ }^{1}$ Clinical Medical college, Yangzhou University, Yangzhou, Jiangsu Province, China. ${ }^{2}$ Department of General Surgery, Institute of General Surgery, Clinica Medical College, Yangzhou University, Northern Jiangsu People's Hospital, Yangzhou 225001, P. R. China.

Received: 13 March 2020 Accepted: 18 May 2020

Published online: 10 June 2020

\section{References}

1. Ge Z, Wu S, Zhang Z, Ding S. Mechanism of tumor cells escaping from immune surveillance of NK cells. Immunopharmacol Immunotoxicol. 2020: $1-12$.

2. Salmaninejad A, Valilou SF, Shabgah AG, Aslani S, Alimardani M, Pasdar A, Sahebkar A. PD-1/PD-L1 pathway: basic biology and role in cancer immunotherapy. J Cell Physiol. 2019;234:16824-37.

3. Alsaab HO, Sau S, Alzhrani R, Tatiparti K, Bhise K, Kashaw SK, Iyer AK. PD-1 and PD-L1 checkpoint signaling inhibition for Cancer immunotherapy: mechanism, combinations, and clinical outcome. Front Pharmacol. 2017;8: 561

4. King-Kallimanis $B L$, Howie $L$, Roydhouse JK, Singh $H$, Theoret MR, Blumenthal GM, Kluetz PG. Patient reported outcomes in anti-PD-1/PD-L1 inhibitor immunotherapy registration trials: FDA analysis of data submitted and future directions. Clin Trials. 2019;16:322-6.

5. Wang Q, Xu R. Immunotherapy-related adverse events (irAEs): extraction from FDA drug labels and comparative analysis. JAMIA Open. 2019;2:173-8.

6. Valentine G, Prince A, Aagaard KM. The neonatal microbiome and Metagenomics: what do we know and what is the future? Neoreviews. 2019;20:e258-71.

7. Laville E, Perrier J, Bejar N, Maresca M, Esque J, Tauzin AS, Bouhajja E, Leclerc $M$, Drula $E$, Henrissat $B$, et al. Investigating host microbiota relationships through functional Metagenomics. Front Microbiol. 2019;10:1286.

8. Frankel AE, Deshmukh S, Reddy A, Lightcap J, Hayes M, McClellan S, Singh S, Rabideau B, Glover TG, Roberts B, Koh AY. Cancer immune checkpoint inhibitor therapy and the gut microbiota. Integr Cancer Ther. 2019;18: 1534735419846379.

9. Fessler J, Matson V, Gajewski TF. Exploring the emerging role of the microbiome in cancer immunotherapy. J Immunother Cancer. 2019;7:108.

10. Zeevi D, Korem T, Godneva A, Bar N, Kurilshikov A, Lotan-Pompan M, Weinberger A, Fu J, Wijmenga C, Zhernakova A, Segal E. Structural variation in the gut microbiome associates with host health. Nature. 2019;568:43-8.

11. Gopalakrishnan V, Helmink BA, Spencer CN, Reuben A, Wargo JA. The influence of the gut microbiome on Cancer, immunity, and Cancer immunotherapy. Cancer Cell. 2018;33:570-80.

12. Zeromski J, Kaczmarek M, Boruczkowski M, Kierepa A, Kowala-Piaskowska A, Mozer-Lisewska I. Significance and role of pattern recognition receptors in malignancy. Arch Immunol Ther Exp. 2019;67:133-41.

13. Brown DG, Soto R, Yandamuri S, Stone C, Dickey L, Gomes-Neto JC, Pastuzyn ED, Bell R, Petersen C, Buhrke K, et al. The microbiota protects from viral-induced neurologic damage through microglia-intrinsic TLR signaling. Elife. 2019;8.

14. Biswas A, Kobayashi KS. Regulation of intestinal microbiota by the NLR protein family. Int Immunol. 2013;25:207-14.

15. Dolasia K, Bisht MK, Pradhan G, Udgata A, Mukhopadhyay S. TLRs/NLRs: shaping the landscape of host immunity. Int Rev Immunol. 2018;37:3-19.

16. Martinon F, Tschopp J. NLRs join TLRs as innate sensors of pathogens. Trends Immunol. 2005;26:447-54

17. Shcheblyakov DV, Logunov DY, Tukhvatulin Al, Shmarov MM, Naroditsky BS, Gintsburg AL. Toll-like receptors (TLRs): the role in tumor progression. Acta Nat. 2010;2:21-9.

18. Dai Z, Zhang J, Wu Q, Chen J, Liu J, Wang L, Chen C, Xu J, Zhang H, Shi C, et al. The role of microbiota in the development of colorectal cancer. Int J Cancer. 2018.

19. Lavelle EC, Murphy C, O'Neill LA, Creagh EM. The role of TLRs, NLRs, and RLRs in mucosal innate immunity and homeostasis. Mucosal Immunol. 2010; 3:17-28.

20. Urban-Wojciuk Z, Khan MM, Oyler BL, Fahraeus R, Marek-Trzonkowska N, Nita-Lazar A, Hupp TR, Goodlett DR. The role of TLRs in anti-cancer immunity and tumor rejection. Front Immunol. 2019;10:2388.

21. Wang L, Yu K, Zhang X, Yu S. Dual functional roles of the MyD88 signaling in colorectal cancer development. Biomed Pharmacother. 2018;107:177-84.

22. Cohen P, Strickson S. The role of hybrid ubiquitin chains in the MyD88 and other innate immune signalling pathways. Cell Death Differ. 2017:24:1153-9.

23. Monie TP, Bryant CE, Gay NJ. Activating immunity: lessons from the TLRs and NLRs. Trends Biochem Sci. 2009:34:553-61.

24. Zhou M, Duan Q, Li Y, Yang Y, Hardwidge PR, Zhu G. Membrane cholesterol plays an important role in enteropathogen adhesion and the activation of innate immunity via flagellin-TLR5 signaling. Arch Microbiol. 2015;197:797803.

25. Oh JZ, Ravindran R, Chassaing B, Carvalho FA, Maddur MS, Bower M, Hakimpour P, Gill KP, Nakaya HI, Yarovinsky F, et al. TLR5-mediated sensing of gut microbiota is necessary for antibody responses to seasonal influenza vaccination. Immunity. 2014:41:478-92.

26. Fukata M, Vamadevan AS, Abreu MT. Toll-like receptors (TLRs) and nod-like receptors (NLRs) in inflammatory disorders. Semin Immunol. 2009;21:242-53.

27. Jo EK. Mycobacterial interaction with innate receptors: TLRs, C-type lectins, and NLRs. Curr Opin Infect Dis. 2008;21:279-86.

28. Kawai T, Akira S. The roles of TLRs, RLRs and NLRs in pathogen recognition. Int Immunol. 2009;21:317-37.

29. Netea MG, van de Veerdonk FL, Kullberg BJ, Van der Meer JW, Joosten LA. The role of NLRs and TLRs in the activation of the inflammasome. Expert Opin Biol Ther. 2008:8:1867-72. 
30. Sharma N, Jha S. NLR-regulated pathways in cancer: opportunities and obstacles for therapeutic interventions. Cell Mol Life Sci. 2016;73:1741-64.

31. Ghimire L, Paudel S, Jin L, Jeyaseelan S. The NLRP6 inflammasome in health and disease. Mucosal Immunol. 2020.

32. Miao EA, Andersen-Nissen E, Warren SE, Aderem A. TLR5 and Ipaf: dual sensors of bacterial flagellin in the innate immune system. Semin Immunopathol. 2007;29:275-88.

33. Bouskra D, Brezillon C, Berard M, Werts C, Varona R, Boneca IG, Eberl G. Lymphoid tissue genesis induced by commensals through NOD1 regulates intestinal homeostasis. Nature. 2008;456:507-10.

34. Couturier-Maillard A, Secher T, Rehman A, Normand S, De Arcangelis A, Haesler R, Huot L, Grandjean T, Bressenot A, Delanoye-Crespin A, et al. NOD2-mediated dysbiosis predisposes mice to transmissible colitis and colorectal cancer. J Clin Invest. 2013;123:700-11.

35. Corridoni D, Arseneau KO, Cominelli F. Functional defects in NOD2 signaling in experimental and human Crohn disease. Gut Microbes. 2014;5:340-4.

36. Ohlsson C, Nigro G, Boneca IG, Backhed F, Sansonetti P, Sjogren K. Regulation of bone mass by the gut microbiota is dependent on NOD1 and NOD2 signaling. Cell Immunol. 2017;317:55-8.

37. Tong L, Xie C, Wei Y, Qu Y, Liang H, Zhang Y, Xu T, Qian X, Qiu H, Deng H. Antitumor effects of Berberine on Gliomas via inactivation of Caspase-1mediated IL-1 beta and IL-18 release. Front Oncol. 2019;9:364.

38. Lemire P, Robertson SJ, Maughan H, Tattoli I, Streutker CJ, Platnich JM Muruve DA, Philpott DJ, Girardin SE. The NLR protein NLRP6 does not impact gut microbiota composition. Cell Rep. 2017;21:3653-61.

39. Wlodarska M, Thaiss CA, Nowarski R, Henao-Mejia J, Zhang JP, Brown EM, Frankel G, Levy M, Katz MN, Philbrick WM, et al. NLRP6 inflammasome orchestrates the colonic host-microbial interface by regulating goblet cell mucus secretion. Cell. 2014;156:1045-59.

40. Henao-Mejia J, Elinav E, Jin C, Hao L, Mehal WZ, Strowig T, Thaiss CA, Kau $A L$, Eisenbarth SC, Jurczak MJ, et al. Inflammasome-mediated dysbiosis regulates progression of NAFLD and obesity. Nature. 2012;482:179-85.

41. Haabeth OAW, Fauskanger M, Manzke M, Lundin KU, Corthay A, Bogen B, Tveita AA. CD4(+) T-cell-mediated rejection of MHC class II-positive tumor cells is dependent on antigen secretion and indirect presentation on host APCs. Cancer Res. 2018;78:4573-85.

42. Grosserichter-Wagener C, Radjabzadeh D, van der Weide H, Smit KN, Kraaij $R$, Hays JP, van Zelm MC. Differences in systemic IgA reactivity and circulating Th subsets in healthy volunteers with specific microbiota Enterotypes. Front Immunol. 2019;10:341.

43. Palm NW, de Zoete MR, Cullen TW, Barry NA, Stefanowski J, Hao L, Degnan $\mathrm{PH}, \mathrm{Hu}$ J, Peter I, Zhang W, et al. Immunoglobulin a coating identifies colitogenic bacteria in inflammatory bowel disease. Cell. 2014;158:1000-10.

44. Pabst O, Cerovic V, Hornef M. Secretory IgA in the coordination of establishment and maintenance of the microbiota. Trends Immunol. 2016; 37:287-96.

45. Macpherson AJ, Yilmaz B, Limenitakis JP, Ganal-Vonarburg SC. IgA function in relation to the intestinal microbiota. Annu Rev Immunol. 2018;36:359-81.

46. Gutzeit C, Magri G, Cerutti A. Intestinal IgA production and its role in hostmicrobe interaction. Immunol Rev. 2014;260:76-85

47. Maruya M, Kawamoto S, Kato LM, Fagarasan S. Impaired selection of IgA and intestinal dysbiosis associated with PD-1-deficiency. Gut Microbes. 2013; 4:165-71.

48. Kawamoto S, Tran TH, Maruya M, Suzuki K, Doi Y, Tsutsui Y, Kato LM, Fagarasan S. The inhibitory receptor PD-1 regulates IgA selection and bacterial composition in the gut. Science. 2012;336:485-9.

49. Derosa L, Routy B, Kroemer G, Zitvogel L. The intestinal microbiota determines the clinical efficacy of immune checkpoint blockers targeting PD-1/PD-L1. Oncoimmunology. 2018;7:e1434468.

50. Sano T, Huang W, Hall JA, Yang Y, Chen A, Gavzy SJ, Lee JY, Ziel JW, Miraldi ER, Domingos Al, et al. An IL-23R/IL-22 circuit regulates epithelial serum amyloid a to promote local effector Th17 responses. Cell. 2015;163:381-93.

51. Sano T, Huang W, Hall JA, Yang Y, Chen A, Gavzy SJ, Lee JY, Ziel JW, Miraldi ER, Domingos Al, et al. An IL-23R/IL-22 circuit regulates epithelial serum amyloid a to promote local effector Th17 responses. Cell. 2016;164:324.

52. Gorczynski RM. IL-17 signaling in the tumor microenvironment. Adv Exp Med Biol. 2020;1240:47-58.

53. Huppler AR, Bishu S, Gaffen SL. Mucocutaneous candidiasis: the IL-17 pathway and implications for targeted immunotherapy. Arthritis Res Ther. 2012;14:217.
54. Kuen DS, Kim BS, Chung Y. IL-17-producing cells in tumor immunity: friends or foes? Immune Netw. 2020;20:e6.

55. Razi S, Baradaran Noveiry B, Keshavarz-Fathi M, Rezaei N. IL-17 and colorectal cancer: from carcinogenesis to treatment. Cytokine. 2019;116:712.

56. Qi W, Huang X, Wang J. Correlation between Th17 cells and tumor microenvironment. Cell Immunol. 2013;285:18-22.

57. Song Y, Yang JM. Role of interleukin (IL)-17 and T-helper (Th)17 cells in cancer. Biochem Biophys Res Commun. 2017;493:1-8.

58. Bienvenu B, Martin B, Auffray C, Cordier C, Becourt C, Lucas B. Peripheral CD8+CD25+ T lymphocytes from MHC class II-deficient mice exhibit regulatory activity. J Immunol. 2005;175:246-53.

59. Khazaie $\mathrm{K}$, von Boehmer $\mathrm{H}$. The impact of CD4+CD25+ Treg on tumor specific CD8+ T cell cytotoxicity and cancer. Semin Cancer Biol. 2006;16: 124-36.

60. Amarnath S, Mangus CW, Wang JC, Wei F, He A, Kapoor V, Foley JE, Massey PR, Felizardo TC, Riley JL, et al. The PDL1-PD1 axis converts human TH1 cells into regulatory T cells. Sci Transl Med. 2011;3:111ra120.

61. Kindlund B, Sjoling A, Yakkala C, Adamsson J, Janzon A, Hansson LE, Hermansson M, Janson P, Winqvist O, Lundin SB. CD4(+) regulatory T cells in gastric cancer mucosa are proliferating and express high levels of IL-10 but little TGF-beta. Gastric Cancer. 2017;20:116-25

62. Torres-Aguilar H, Sanchez-Torres C, Jara LJ, Blank M, Shoenfeld Y. IL-10/TGFbeta-treated dendritic cells, pulsed with insulin, specifically reduce the response to insulin of CD4+ effector/memory T cells from type 1 diabetic individuals. J Clin Immunol. 2010;30:659-68.

63. Dutta A, Huang CT, Chen TC, Lin CY, Chiu CH, Lin YC, Chang CS, He YC. IL10 inhibits neuraminidase-activated TGF-beta and facilitates Th1 phenotype during early phase of infection. Nat Commun. 2015;6:6374.

64. Kumar NP, Moideen K, George PJ, Dolla C, Kumaran P, Babu S. Coincident diabetes mellitus modulates Th1-, Th2-, and Th17-cell responses in latent tuberculosis in an IL-10- and TGF-beta-dependent manner. Eur J Immunol. 2016:46:390-9.

65. Sun $M$, Wu W, Chen L, Yang W, Huang X, Ma C, Chen F, Xiao Y, Zhao Y, Ma $C$, et al. Microbiota-derived short-chain fatty acids promote Th1 cell IL-10 production to maintain intestinal homeostasis. Nat Commun. 2018;9:3555.

66. Cottrez F, Groux H. Regulation of TGF-beta response during T cell activation is modulated by IL-10. J Immunol. 2001;167:773-8.

67. Hori S, Nomura T, Sakaguchi S. Control of regulatory T cell development by the transcription factor Foxp3. Science. 2003;299:1057-61.

68. Blandford LE, Johnston EL, Sanderson JD, Wade WG, Lax AJ. Promoter orientation of the immunomodulatory Bacteroides fragilis capsular polysaccharide a (PSA) is off in individuals with inflammatory bowel disease (IBD). Gut Microbes. 2019;10:569-77.

69. Johnson $\mathrm{J}$, Jones MB, Cobb BA. Polysaccharide-experienced effector T cells induce $\mathrm{IL}-10$ in FoxP3+ regulatory T cells to prevent pulmonary inflammation. Glycobiology. 2018;28:50-8.

70. Bisaccia J. Soudja S: [microbiome-derived butyrate alleviates intestinal graft versus host reaction]. Med Sci (Paris). 2017;33:862-4.

71. Donohoe DR, Garge N, Zhang X, Sun W, O'Connell TM, Bunger MK, Bultman $\mathrm{SJ}$. The microbiome and butyrate regulate energy metabolism and autophagy in the mammalian colon. Cell Metab. 2011;13:517-26.

72. Akel S, Bertolette D, Ruscetti FW. Crosstalk between the Smad and the Mitogen-Activated Protein Kinase Pathways is Essential for Erythroid Differentiation of Erythroleukemia Cells Induced by TGF-beta, Activin, Hydroxyurea and Butyrate. J Leuk (Los Angel). 2013:1.

73. Martin-Gallausiaux C, Beguet-Crespel F, Marinelli L, Jamet A, Ledue F, Blottiere HM, Lapaque N. Butyrate produced by gut commensal bacteria activates TGF-beta1 expression through the transcription factor SP1 in human intestinal epithelial cells. Sci Rep. 2018:8:9742.

74. Schiavinato J, Haddad R, Saldanha-Araujo F, Baiochi J, Araujo AG, Santos Scheucher P, Covas DT, Zago MA, Panepucci RA. TGF-beta/atRA-induced Tregs express a selected set of microRNAs involved in the repression of transcripts related to Th17 differentiation. Sci Rep. 2017:7:3627.

75. Zhou L, Lopes JE, Chong MM. Ivanov, II, min R, Victora GD, Shen Y, Du J, Rubtsov YP, Rudensky AY, et al: TGF-beta-induced Foxp3 inhibits $T(H) 17$ cell differentiation by antagonizing RORgammat function. Nature. 2008;453:23640.

76. Yang J, Xu L. Elevated IL-23R expression and Foxp3+Rorgt+ cells in intestinal mucosa during acute and chronic colitis. Med Sci Monit. 2016:22: 2785-92. 
77. Miao X, Xu R, Fan B, Chen J, Li X, Mao W, Hua S, Li B. PD-L1 reverses depigmentation in Pmel-1 vitiligo mice by increasing the abundance of Tregs in the skin. Sci Rep. 2018:8:1605

78. Alegre ML, Bromberg JS, Bromberg JS. Commensal microbiota determine intestinal iTreg. Am J Transplant. 2012;12:1967.

79. Omenetti S, Pizarro TT. The Treg/Th17 Axis: a dynamic balance regulated by the gut microbiome. Front Immunol. 2015;6:639.

80. Francisco LM, Salinas VH, Brown KE, Vanguri VK, Freeman GJ, Kuchroo VK, Sharpe AH. PD-L1 regulates the development, maintenance, and function of induced regulatory T cells. J Exp Med. 2009;206:3015-29.

81. Zhao R, Song Y, Wang Y, Huang Y, Li Z, Cui Y, Yi M, Xia L, Zhuang W, Wu X, Zhou Y. PD-1/PD-L1 blockade rescue exhausted CD8+ T cells in gastrointestinal stromal tumours via the PI3K/Akt/mTOR signalling pathway. Cell Prolif. 2019;52:e12571.

82. Ohue Y, Nishikawa H. Regulatory T (Treg) cells in cancer: can Treg cells be a new therapeutic target? Cancer Sci. 2019;110:2080-9.

83. Cai J, Wang D, Zhang G, Guo X. The role of PD-1/PD-L1 Axis in Treg development and function: implications for Cancer immunotherapy. Onco Targets Ther. 2019;12:8437-45.

84. Kamimura N, Wolf AM, Iwai Y. Development of Cancer immunotherapy targeting the PD-1 pathway. J Nippon Med Sch. 2019;86:10-4

85. Callea M, Pedica F, Doglioni C. Programmed death 1 (PD-1) and its ligand (PD-L1) as a new frontier in cancer immunotherapy and challenges for the pathologist: state of the art. Pathologica. 2016;108:48-58.

86. Zheng P, Zhou Z. Human Cancer immunotherapy with PD-1/PD-L1 blockade. Biomark Cancer. 2015;7:15-8.

87. Chae YK, Arya A, lams W, Cruz MR, Chandra S, Choi J, Giles F. Current landscape and future of dual anti-CTLA4 and PD-1/PD-L1 blockade immunotherapy in cancer; lessons learned from clinical trials with melanoma and non-small cell lung cancer (NSCLC). J Immunother Cancer. 2018;6:39.

88. Masteller EL, Chuang E, Mullen AC, Reiner SL, Thompson CB. Structural analysis of CTLA-4 function in vivo. J Immunol. 2000;164:5319-27.

89. Rotte A. Combination of CTLA-4 and PD-1 blockers for treatment of cancer. J Exp Clin Cancer Res. 2019;38:255.

90. Callahan MK, Wolchok JD. At the bedside: CTLA-4- and PD-1-blocking antibodies in cancer immunotherapy. J Leukoc Biol. 2013;94:41-53.

91. Stamper CC, Zhang Y, Tobin JF, Erbe DV, Ikemizu S, Davis SJ, Stahl ML, Seehra J, Somers WS, Mosyak L. Crystal structure of the B7-1/CTLA-4 complex that inhibits human immune responses. Nature. 2001;410:608-11.

92. Ganesan A, Moon TC, Barakat KH. Revealing the atomistic details behind the binding of B7-1 to CD28 and CTLA-4: a comprehensive protein-protein modelling study. Biochim Biophys Acta Gen Subj. 1862;2018:2764-78.

93. Linterman MA, Denton AE. Treg cells and CTLA-4: the ball and chain of the germinal center response. Immunity. 2014;41:876-8.

94. Tanaka A, Sakaguchi S. Targeting Treg cells in cancer immunotherapy. Eur J Immunol. 2019.

95. Hargadon KM, Johnson CE, Williams CJ. Immune checkpoint blockade therapy for cancer: an overview of FDA-approved immune checkpoint inhibitors. Int Immunopharmacol. 2018;62:29-39.

96. Pluim D, Ros W, Miedema IHC, Beijnen JH, Schellens JHM. Multiparameter flow Cytometry assay for quantification of immune cell subsets, PD-1 expression levels and PD-1 receptor occupancy by Nivolumab and Pembrolizumab. Cytometry A. 2019;95(10):1053.

97. Lee HT, Lee JY, Lim H, Lee SH, Moon YJ, Pyo HJ, Ryu SE, Shin W, Heo YS. Molecular mechanism of PD-1/PD-L1 blockade via anti-PD-L1 antibodies atezolizumab and durvalumab. Sci Rep. 2017;7:5532.

98. Hellmann MD, Paz-Ares L, Bernabe Caro R, Zurawski B, Kim SW, Carcereny Costa E, Park K, Alexandru A, Lupinacci L, de la Mora JE, et al. Nivolumab plus Ipilimumab in advanced non-small-cell lung Cancer. N Engl J Med. 2019.

99. Topalian SL, Hodi FS, Brahmer JR, Gettinger SN, Smith DC, McDermott DF, Powderly JD, Carvajal RD, Sosman JA, Atkins MB, et al. Safety, activity, and immune correlates of anti-PD-1 antibody in cancer. N Engl J Med. 2012;366: 2443-54.

100. Robert C, Long GV, Brady B, Dutriaux C, Maio M, Mortier L, Hassel JC, Rutkowski P, McNeil C, Kalinka-Warzocha E, et al. Nivolumab in previously untreated melanoma without BRAF mutation. N Engl J Med. 2015;372:32030.

101. Mok TSK, Wu YL, Kudaba I, Kowalski DM, Cho BC, Turna HZ, Castro G Jr, Srimuninnimit V, Laktionov KK, Bondarenko I, et al. Pembrolizumab versus chemotherapy for previously untreated, PD-L1-expressing, locally advanced or metastatic non-small-cell lung cancer (KEYNOTE-042): a randomised, open-label, controlled, phase 3 trial. Lancet. 2019;393:1819-30.

102. Shigematsu Y, Inamura K. Gut microbiome: a key player in cancer immunotherapy. Hepatobiliary Surg Nutr. 2018;7:479-80.

103. Hodi FS, Chiarion-Sileni V, Gonzalez R, Grob JJ, Rutkowski P, Cowey CL, Lao $C D$, Schadendorf D, Wagstaff J, Dummer R, et al. Nivolumab plus ipilimumab or nivolumab alone versus ipilimumab alone in advanced melanoma (CheckMate 067): 4-year outcomes of a multicentre, randomised, phase 3 trial. Lancet Oncol. 2018;19:1480-92.

104. Rozeman EA, Menzies AM, van Akkooi ACJ, Adhikari C, Bierman C, van de Wiel BA, Scolyer RA, Krijgsman O, Sikorska K, Eriksson H, et al. Identification of the optimal combination dosing schedule of neoadjuvant ipilimumab plus nivolumab in macroscopic stage III melanoma (OpACIN-neo): a multicentre, phase 2, randomised, controlled trial. Lancet Oncol. 2019;20: 948-60

105. Spitzer MH, Carmi Y, Reticker-Flynn NE, Kwek SS, Madhireddy D, Martins MM, Gherardini PF, Prestwood TR, Chabon J, Bendall SC, et al. Systemic immunity is required for effective Cancer immunotherapy. Cell. 2017;168: 487-502 e415.

106. Su Q, Zhang XC, Wang DY, Zhang HR, Zhu C, Hou YL, Liu JL, Gao ZH. The risk of immune-related endocrine disorders associated with anti-PD-1 inhibitors therapy for solid tumors: a systematic review and meta-analysis. Int Immunopharmacol. 2018;59:328-38.

107. Gu L, Khadaroo PA, Su H, Kong L, Chen L, Wang X, Li X, Zhu H, Zhong X, Pan J, Chen M. The safety and tolerability of combined immune checkpoint inhibitors (anti-PD-1/PD-L1 plus anti-CTLA-4): a systematic review and metaanalysis. BMC Cancer. 2019;19:559.

108. Yi M, Qin S, Chu Q, Wu K. The role of gut microbiota in immune checkpoint inhibitor therapy. Hepatobiliary Surg Nutr. 2018;7:481-3.

109. Sivan A, Corrales L, Hubert N, Williams JB, Aquino-Michaels K, Earley ZM, Benyamin FW, Lei YM, Jabri B, Alegre ML, et al. Commensal Bifidobacterium promotes antitumor immunity and facilitates anti-PD-L1 efficacy. Science. 2015;350:1084-9.

110. Yi M, Yu S, Qin S, Liu Q, Xu H, Zhao W, Chu Q, Wu K. Gut microbiome modulates efficacy of immune checkpoint inhibitors. J Hematol Oncol. 2018; $11: 47$

111. Chaput N, Lepage P, Coutzac C, Soularue E, Le Roux K, Monot C, Boselli L, Routier E, Cassard L, Collins M, et al. Baseline gut microbiota predicts clinical response and colitis in metastatic melanoma patients treated with ipilimumab. Ann Oncol. 2017;28:1368-79.

112. Eisenhauer EA, Therasse P, Bogaerts J, Schwartz LH, Sargent D, Ford R, Dancey J, Arbuck S, Gwyther S, Mooney M, et al. New response evaluation criteria in solid tumours: revised RECIST guideline (version 1.1). Eur J Cancer. 2009:45:228-47.

113. Routy B, Le Chatelier E, Derosa L, Duong CPM, Alou MT, Daillere R, Fluckiger A, Messaoudene M, Rauber C, Roberti MP, et al. Gut microbiome influences efficacy of PD-1-based immunotherapy against epithelial tumors. Science. 2018;359:91-7.

114. Sears CL, Pardoll DM. The intestinal microbiome influences checkpoint blockade. Nat Med. 2018;24:254-5.

115. Frankel AE, Coughlin LA, Kim J, Froehlich TW, Xie Y, Frenkel EP, Koh AY. Metagenomic shotgun sequencing and unbiased Metabolomic profiling identify specific human gut microbiota and metabolites associated with immune checkpoint therapy efficacy in melanoma patients. Neoplasia. 2017: 19:848-55.

116. Vetizou M, Pitt JM, Daillere R, Lepage P, Waldschmitt N, Flament C, Rusakiewicz S, Routy B, Roberti MP, Duong CP, et al. Anticancer immunotherapy by CTLA-4 blockade relies on the gut microbiota. Science. 2015:350:1079-84.

117. Arumugam M, Raes J, Pelletier E, Le Paslier D, Yamada T, Mende DR, Fernandes GR, Tap J, Bruls T, Batto JM, et al. Enterotypes of the human gut microbiome. Nature. 2011;473:174-80

118. Qin J, Li R, Raes J, Arumugam M, Burgdorf KS, Manichanh C, Nielsen T, Pons $\mathrm{N}$, Levenez F, Yamada T, et al. A human gut microbial gene catalogue established by metagenomic sequencing. Nature. 2010;464:59-65.

119. Pitt JM, Vetizou M, Waldschmitt N, Kroemer G, Chamaillard M, Boneca IG, Zitvogel L. Fine-tuning Cancer immunotherapy: optimizing the gut microbiome. Cancer Res. 2016;76:4602-7.

120. Pitt JM, Vetizou M, Gomperts Boneca I, Lepage P, Chamaillard M, Zitvogel L. Enhancing the clinical coverage and anticancer efficacy of immune 
checkpoint blockade through manipulation of the gut microbiota. Oncoimmunology. 2017;6:e1132137.

121. Wang Y, Ma R, Liu F, Lee SA, Zhang L. Modulation of gut microbiota: a novel paradigm of enhancing the efficacy of programmed Death-1 and programmed death Ligand-1 blockade therapy. Front Immunol. 2018;9:374.

122. Matson V, Fessler J, Bao R, Chongsuwat T, Zha Y, Alegre ML, Luke JJ, Gajewski TF. The commensal microbiome is associated with anti-PD-1 efficacy in metastatic melanoma patients. Science. 2018;359:104-8.

123. Gopalakrishnan V, Spencer CN, Nezi L, Reuben A, Andrews MC, Karpinets TV, Prieto PA, Vicente D, Hoffman K, Wei SC, et al. Gut microbiome modulates response to anti-PD-1 immunotherapy in melanoma patients. Science. 2018; 359:97-103.

124. Liu J, Rozeman EA, O'Donnell JS, Allen S, Fanchi L, Smyth MJ, Blank CU, Teng MWL. Batf3(+) DCs and type I IFN are critical for the efficacy of neoadjuvant cancer immunotherapy. Oncoimmunology. 2019;8:e1546068.

125. Nakiboneka R, Mugaba S, Auma BO, Kintu C, Lindan C, Nanteza MB, Kaleebu $\mathrm{P}$, Serwanga J. Interferon gamma (IFN-gamma) negative CD4+ and CD8+ Tcells can produce immune mediators in response to viral antigens. Vaccine. 2019;37:113-22

126. Robertson J, Haas CT, Pele LC, Monie TP, Charalambos C, Parkes M, Hewitt RE, Powell JJ. Intestinal APCs of the endogenous nanomineral pathway fail to express PD-L1 in Crohn's disease. Sci Rep. 2016;6:26747.

127. Swafford D, Shanmugam A, Ranganathan P, Hussein MS, Koni PA, Prasad $\mathrm{PD}$, Thangaraju M, Manicassamy S. Canonical Wnt signaling in CD11C(+) APCs regulates microbiota-induced inflammation and immune cell homeostasis in the Colon. J Immunol. 2018;200:3259-68.

128. Daillere R, Vetizou M, Waldschmitt N, Yamazaki T, Isnard C, Poirier-Colame V, Duong CPM, Flament C, Lepage P, Roberti MP, et al. Enterococcus hirae and Barnesiella intestinihominis facilitate cyclophosphamide-induced therapeutic Immunomodulatory effects. Immunity. 2016;45:931-43.

129. Cong J, Zhang X. Roles of intestinal microbiota in response to cancer immunotherapy. Eur J Clin Microbiol Infect Dis. 2018;37:2235-40.

130. Pandiyan P, Bhaskaran N, Zou M, Schneider E, Jayaraman S, Huehn J. Microbiome dependent regulation of Tregs and Th17 cells in mucosa. Front Immunol. 2019;10:426.

131. Britton GJ, Contijoch EJ, Mogno I, Vennaro OH, Llewellyn SR, Ng R, Li Z, Mortha A, Merad M, Das A, et al. Microbiotas from humans with inflammatory bowel disease Alter the balance of gut Th17 and RORgammat(+) regulatory T cells and exacerbate colitis in mice. Immunity. 2019:50:212-24 e214.

132. Xu C, Ruan B, Jiang Y, Xue T, Wang Z, Lu H, Wei M, Wang S, Ye Z, Zhai D, et al. Antibiotics-induced gut microbiota dysbiosis promotes tumor initiation via affecting APC-Th1 development in mice. Biochem Biophys Res Commun. 2017:488:418-24.

133. Minarrieta L, Ghorbani P, Sparwasser T, Berod L. Metabolites: deciphering the molecular language between DCs and their environment. Semin Immunopathol. 2017;39:177-98.

134. Vogt A, Sievers E, Lukacs-Kornek V, Decker G, Raskopf E, Meumann N, Buning H, Sauerbruch T, Strassburg CP, Schmidt-Wolf IG, Gonzalez-Carmona MA. Improving immunotherapy of hepatocellular carcinoma (HCC) using dendritic cells (DC) engineered to express IL-12 in vivo. Liver Int. 2014;34: $447-61$

135. Ma N, Xing C, Xiao H, Wang Y, Wang K, Hou C, Han G, Chen G, Marrero B, Wang $Y$, et al. C5a regulates IL-12+ DC migration to induce pathogenic Th1 and Th17 cells in sepsis. PLoS One. 2013;8:e69779.

136. Paust HJ, Riedel JH, Krebs CF, Turner JE, Brix SR, Krohn S, Velden J, Wiech T, Kaffke $A$, Peters $A$, et al. CXCR3+ regulatory T cells control TH1 responses in Crescentic GN. J Am Soc Nephrol. 2016;27:1933-42.

137. Jacquelot N, Enot DP, Flament C, Vimond N, Blattner C, Pitt JM, Yamazaki T, Roberti MP, Daillere R, Vetizou M, et al. Chemokine receptor patterns in lymphocytes mirror metastatic spreading in melanoma. J Clin Invest. 2016; 126:921-37.

138. Kadowaki A, Saga R, Lin Y, Sato W, Yamamura T. Gut microbiota-dependent CCR9+CD4+ $\mathrm{T}$ cells are altered in secondary progressive multiple sclerosis. Brain. 2019;142:916-31

139. Cosorich I, McGuire HM, Warren J, Danta M, King C. CCR9 expressing T helper and T follicular helper cells exhibit site-specific identities during inflammatory disease. Front Immunol. 2018;9:2899.

140. Jing L, Laing KJ, Dong L, Russell RM, Barlow RS, Haas JG, Ramchandani MS, Johnston C, Buus S, Redwood AJ, et al. Extensive CD4 and CD8 T cell crossreactivity between Alphaherpesviruses. J Immunol. 2016;196:2205-18.
141. Balachandran VP, Luksza M, Zhao JN, Makarov V, Moral JA, Remark R, Herbst B, Askan G, Bhanot U, Senbabaoglu Y, et al. Identification of unique neoantigen qualities in long-term survivors of pancreatic cancer. Nature. 2017:551:512-6.

142. Li W, Deng Y, Chu Q, Zhang P. Gut microbiome and cancer immunotherapy. Cancer Lett. 2019;447:41-7.

143. Yi M, Jiao D, Qin S, Chu Q, Li A, Wu K. Manipulating gut microbiota composition to enhance the therapeutic effect of Cancer immunotherapy. Integr Cancer Ther. 2019;18:1534735419876351.

144. Inamura K. Roles of microbiota in response to cancer immunotherapy. Semin Cancer Biol. 2020

145. Sun JY, Yin TL, Zhou J, Xu J, Lu XJ. Gut microbiome and cancer immunotherapy. J Cell Physiol. 2020;235:4082-8.

146. Sarrabayrouse G, Alameddine J, Altare F, Jotereau F. Microbiota-specific CD4CD8alphaalpha Tregs: role in intestinal immune homeostasis and implications for IBD. Front Immunol. 2015;6:522.

147. Morrison DJ, Preston T. Formation of short chain fatty acids by the gut microbiota and their impact on human metabolism. Gut Microbes. 2016;7: 189-200.

148. Arpaia N, Campbell C, Fan X. Dikiy S, van der Veeken J, deRoos P, Liu H, cross JR, Pfeffer $\mathrm{K}$, coffer PJ, Rudensky AY: metabolites produced by commensal bacteria promote peripheral regulatory T-cell generation. Nature. 2013;504:451-5.

149. Furusawa Y, Obata Y, Fukuda S, Endo TA, Nakato G, Takahashi D, Nakanishi Y, Uetake C, Kato K, Kato T, et al. Commensal microbe-derived butyrate induces the differentiation of colonic regulatory T cells. Nature. 2013;504: $446-50$

150. Smith PM, Howitt MR, Panikov N, Michaud M, Gallini CA, Bohlooly YM, Glickman JN, Garrett WS. The microbial metabolites, short-chain fatty acids, regulate colonic Treg cell homeostasis. Science. 2013;341:569-73.

151. Irrazabal T, Martin A. T regulatory cells gone bad: an oncogenic immune response against Enterotoxigenic B. fragilis infection leads to Colon Cancer. Cancer Discov. 2015;5:1021-3.

152. Wei SC, Levine JH, Cogdill AP, Zhao Y, Anang NAS, Andrews MC, Sharma P Wang J, Wargo JA, Pe'er D, Allison JP. Distinct cellular mechanisms underlie anti-CTLA-4 and anti-PD-1 checkpoint blockade. Cell. 2017;170:1120-33 e1117.

153. Wolchok JD, Rollin L, Larkin J. Nivolumab and Ipilimumab in advanced melanoma. N Engl J Med. 2017;377:2503-4.

154. Wolchok JD, Chiarion-Sileni V, Gonzalez R, Rutkowski P, Grob JJ, Cowey CL, Lao CD, Wagstaff J, Schadendorf D, Ferrucci PF, et al. Overall survival with combined Nivolumab and Ipilimumab in advanced melanoma. N Engl J Med. 2017:377:1345-56.

155. Routy B, Gopalakrishnan V, Daillere R, Zitvogel L, Wargo JA, Kroemer G. The gut microbiota influences anticancer immunosurveillance and general health. Nat Rev Clin Oncol. 2018;15:382-96.

156. Temraz S, Nassar F, Nasr R, Charafeddine M, Mukherii D, Shamseddine A. Gut microbiome: a promising biomarker for immunotherapy in colorectal Cancer. Int J Mol Sci. 2019;20.

157. Wang T, Zheng N, Luo Q, Jiang L, He B, Yuan X, Shen L. Probiotics lactobacillus reuteri abrogates immune checkpoint blockade-associated colitis by inhibiting group 3 innate lymphoid cells. Front Immunol. 2019;10:1235.

158. Sun MC, Zhang FC, Yin X, Cheng BJ, Zhao CH, Wang YL, Zhang ZZ, Hao HW, Zhang TH, Ye HQ. Lactobacillus reuteri F-9-35 prevents DSS-induced colitis by inhibiting Proinflammatory gene expression and restoring the gut microbiota in mice. J Food Sci. 2018:83:2645-52.

159. Mayer C, Brachhold K. Molecular nutrition-from gut microbiota to metabolomics and inter-individual nutrition. Mol Nutr Food Res. 2019;63:e1970005.

160. Weber C. Nutrition. Diet change alters microbiota and might affect cancer risk. Nat Rev Gastroenterol Hepatol. 2015:12:314

161. Vetizou M, Daillere R. Zitvogel L: [the role of intestinal microbiota in the response to anti-tumor therapies]. Med Sci (Paris). 2016;32:974-82.

162. Zebertavage L, Bambina S, Shugart J, Alice A, Zens KD, Lauer P, Hanson B, Gough MJ, Crittenden MR, Bahjat KS. A microbial-based cancer vaccine for induction of EGFRvlll-specific CD8+ T cells and anti-tumor immunity. PLoS One. 2019;14:e0209153.

163. D'Haens GR, Jobin C. Fecal microbial transplantation for diseases beyond recurrent Clostridium Difficile infection. Gastroenterology. 2019.

\section{Publisher's Note}

Springer Nature remains neutral with regard to jurisdictional claims in published maps and institutional affiliations. 